\title{
Study on cracks and process improvement for case hardened gear shaft straightening
}

\section{Wenzhen Ma}

The Institute of Manufacturing Engineering,Zhejiang University

Hongyao Shen ( $\sim$ shenhongyao@zju.edu.cn )

The Institute of Manufacturing Engineering,Zhejiang University https://orcid.org/0000-0002-4391-1950

\section{Guanhua Xu}

Zhejiang University

\section{Research Article}

Keywords: Gear shaft, Pressure straightening, Heat treatment, Crack, Finite element simulation

Posted Date: February 24th, 2021

DOI: https://doi.org/10.21203/rs.3.rs-231810/v1

License: (c) (i) This work is licensed under a Creative Commons Attribution 4.0 International License.

Read Full License 


\title{
Study on cracks and process improvement for case hardened gear shaft straightening
}

\author{
Wenzhen $\mathrm{Ma}^{1,2}$, Hongyao Shen ${ }^{1,2^{*}}$, Guanhua $\mathrm{Xu}^{1}$
}

1.State Key Laboratory of Fluid Power and Mechatronic Systems, College of Mechanical Engineering, Zhejiang

University, Hangzhou, 310027, China.

2.Polytechnic Institute, Zhejiang University, Hangzhou, 310027, China.

\begin{abstract}
Gear shaft is one of the key components for transmitting torque and speed in automotive transmission. Deflections will inevitably occur after heat treatment. It is necessary to ensure the straightness of the parts by straightening. During straightening process, cracks often appear and result in scrapped parts. This paper focuses on the situation of high straightening crack rate of internal input shaft in one dual-clutch automotive transmission, makes an in-depth analyses the pressure straightening process theory, crack generation mechanism, working process and crack detection system. After studying on the case hardened gear shaft material properties, elastoplastic process theoretical basis, crack characteristic and finite element simulation, etc., This paper has systematically improved straightening crack performance and proposes three crack rate improvement methods by using finite element analysis to find out optimal punch point which can reduce the maximum stress value; increasing the punch increments and adopt vector straightening to improve the straightening procedure; reducing the gas quenching pressure in the heat treatment process to improve the mechanical properties of the parts, etc. Finally, the scrap rate of straightening crack was reduced from $1.95 \%$ to $0.14 \%$.
\end{abstract}

Keywords: Gear shaft, Pressure straightening, Heat treatment, Crack, Finite element simulation

\section{Introduction}

Transmission is a set of transfer device in automobile which used to coordinate the engine speed and the actual driving speed of the wheels, it's the transmission center of the automobile, mainly used to transmit the speed and torque that generated by engine. Gear shaft is one of the key components for transmitting torque and speed in automotive transmission. During the production of gear shafts, the parts will show different degrees of deflection after heat treatment, and it need to be straightened to meet the straightness requirements of the parts. For the gear shaft parts, it's generally adopts pressure straightening methods.

Pressure straightening is known as three-point reverse bending straightening. The main process is to hinge the two ends of the part first, and then apply a reverse force at the place with the maximum deflection to cause reverse deformation. after the external force remove, a part of the workpiece springback, while the other part permanently deformed. If the permanent deformation reaches the initial deflection, the workpiece is straightened. Straightening crack often occurs during straightening the internal input shaft and resulting in scrap. This paper focuses on the situation of high straightening crack rate which up to $1.95 \%$ of internal input shaft in one dual-clutch automotive transmission, study on the gear shaft straightening theory and related process, do some corresponding improvements to reduce the straightening crack rate. Fig. 1 shows the internal input shaft picture. Fig. 2 shows the straightening crack.

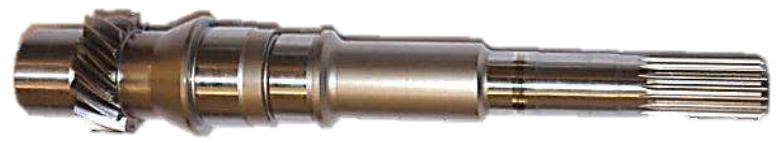

Fig. 1. Internal input shaft

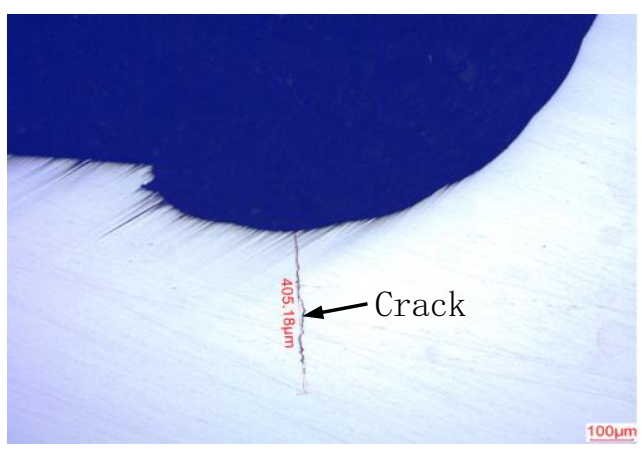

Fig. 2. Straightening crack

*Corresponding author.

E-mail address: shenhongyao@zju.edu.cn 
At present, research on pressure straightening theory and technology which based on elastoplastic theory are mainly two basic problems: the combination of punch-anvil and the displacement of punch. Among them, the study of puch displacement is the most critical and the most difficult issue, and it is also the hot pot of current straightening theoretical research. Stelson et al. [1-3] did a lot of pioneering work on the intelligent control of V-bending in the 1980s. Starting from the load-displacement curve, he developed an adaptive control method that can effectively control the displacement of punch in real time according to the theoretical model derived from elastoplastic mechanics. Talukder and Singh [4] conducted a more systematic elastoplastic mechanical analysis of the pressure straightening reverse bending process which laid a good theoretical foundation for pressure straightening technology. Katoh et al. [5-6] studied the real-time control of seamless steel pipe straightening, it's not only introduced the hydraulic system and detection system of straightening equipment in detail, but also introduced the use of empirical formulas to predict the springback of parts based on the elastoplastic theory. Murata et al. [7] found that parameters such as bending radius, springback and stress distribution during workpiece straightening were significantly affected by the work hardening of the material through finite element numerical simulation. Eggertsen and Mattiasson [8] based on this research, in order to more accurately predict the springback of pressure straightening, through the modeling process of reverse bending straightening, the springback of different material strengthening models were analyzed and compared. Megharbel et al. [9] calculated the residual stress and springback during the straightening process of the parts through the Al-Qureshi algorithm, with certain reliability. Schleinzer and Fischer [10-11] studied the stress superposition and Bauschinger effect during the straightening process, and proposed the influence of punch displacement on the straightening process. Kim and Chung SC. [12-13] conducted a more in-depth study on the multi-step straightening control system, and introduced a fuzzy self-learning algorithm in the straightening process to compensate for the increment of the punch during straightening process. In addition It also elaborates the influence of the straightening punch point on other straightening points, and takes this effect as an important consideration for the selection of punches and anvils when the part is straightened. Zhai [14] based on the multi-step straightening process to classify the bending deformation on the basis of elastoplastic deformation, and adopted different punch-anvil combination straightening strategies for each type of bending. Through a lot of experiments, the work load-deflection equation is optimized, and the punch control based on deformation is effectively achieved. Zhao [15] used finite element analysis to study the mechanical properties of the three-point pressure straightening, and the analysis results can be an effective reference for the selection of punch points during pressure straightening.

Nowadays, straightening theory has been studied in depth, but it needs to be improved in practical application, such as less research on the straightening process for transmission gear shafts which case hardened by heat treatment in the literature. For this type of part straightening, not only should pay attention to how to straighten the bent parts effectively, but also need consider how to reduce the straightening crack rate, Currently lack of systematic improvement studies to meet the needs of mass production.

\section{Gear shaft pressure straightening theory and straightening crack mechanism analysis}

\subsection{Process of gear shaft straightening}

Fig. 3 shows the load-deflection curve of straightening process, $F$ s corresponding to point $\mathrm{A}$ is the yield load, Plastic deformation occurs when $F>F \mathrm{~s}$. $F$ b corresponding to point B is the tensile load. Straightening crack occurs when $F>$ $F \mathrm{~b}$, Therefore, the load $F$ for part alignment should satisfy: $F \mathrm{~s}<\mathrm{F}<F \mathrm{~b}$ 。

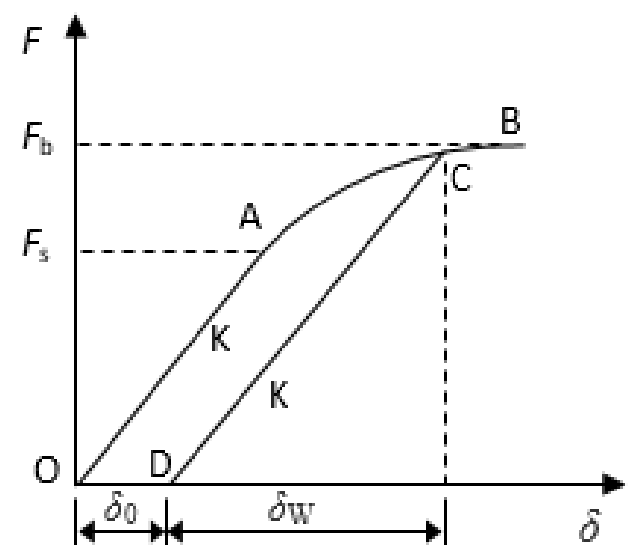

Fig. 3. Elastoplastic pressure straightening process model

It can be seen from Fig. 3 that the straightening process is divided into three stages: the elastic deformation stage OA, the elastoplastic deformation stage AC and the springback stage $\mathrm{CD}$. After loading, the OA stage is purely elastic deformation, and point $\mathrm{A}$ is at the elastic bending limit. This stage conforms to Hooke's law; continue to load to point $\mathrm{C}$ 
and unload, $\mathrm{AC}$ is the elastoplastic deformation stage, at this stage plastic deformation occurs in some areas near the punch point, And the proportion continues to increase, so the slope continues to decrease; because part of the plastic deformation has occurred, the parts can only rebound to point $\mathrm{D}$ after unloading,. It assumes that the springback amount is $\delta_{\mathrm{w}}$, and the plastic bending amount is $\delta_{0}$. If the initial bending amount is also $\delta_{0}$, the part finish straightening. the straightening displacement $\delta_{\Sigma}=\delta_{0}+\delta_{\mathrm{w}}$.

At present, the straightening pressure $F$ is not easy to be accurately controlled in real time, while the straightening displacement $\delta_{\Sigma}$ can be accurately controlled in real time by the precision electro-hydraulic servo system, so the most of automatic straightening machines implement precise straightening by controlling the punch displacement ${ }^{[1]}$. Since the shape and structure of the transmission gear shaft and the initial stress distribution are relatively complicated, and the material properties between surface and the core of the parts are basically different after surface carburization, so there is no mature algorithm for reference in the actual straightening process. At present, mainly uses multi-step straightening methods for the gear shaft which after surface hardening treatment [16].

When the stress exceeds elastic yield limit, it goes to elastoplastic deformation stage. Fig. 4 shows the elastoplastic zone division of the gear shaft after load pressure. Zone 1 is the elastoplastic compression zone, zone 2 and zone 4 are rigidly rotated, zone 3 is the elastic deformation stage, and zone 5 is the elastoplastic stretching zone.

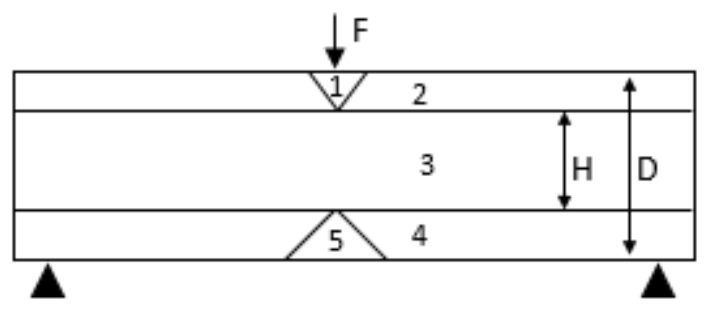

Fig. 4. Division of elastoplastic deformation region

From the calculation of the material mechanics formula, it can be seen that when the shaft is in elastic deformation, the maximum tensile stress at the bottom surface of the part at the punch point, it can be calculated as:

$$
\sigma_{\max }=\frac{32 M}{\pi D^{3}}
$$

In the elastoplastic deformation stage, based on the elastic linear strengthening model, the maximum stress at the lower surface of the part can be obtained and calculated as:

$$
\sigma_{\max }=\sigma_{\mathrm{s}}+\lambda \sigma_{\mathrm{s}}\left(\frac{1}{\xi}-1\right)
$$

where $\lambda=E_{\mathrm{p}} / E, E_{\mathrm{p}}$ is the strengthened elastic modulus, $E$ is the initial elastic modulus, $\sigma_{\mathrm{s}}$ is the yield strength, and $\xi$ is the elastic yield ratio, $\xi=\frac{H}{D}$.

\subsection{Parts bending forms}

The bending of the gear shaft after heat treatment mainly includes the following forms as Fig. 5 shows :

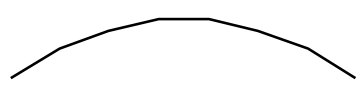

(1) Single bending

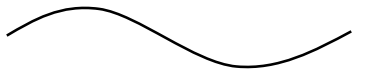

(2) S shape

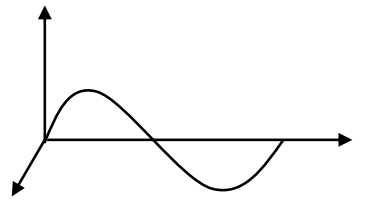

(3) Space distorting

Fig. 5. Bending forms of gear shaft

The output shaft of the dual-clutch transmission is stubby and generally present single-bending type after heat treatment, while the slender inner input shaft has a variety of deformation forms such as single-bending, S-shaped, and spacedistorting types. The single-bending type conforms to the classic three-point reverse bending straightening model is relatively easy to be straighten, but unreasonable straightening process may also align single-bending shafts into S-shaped or space-distorted types, while straightening of S-shaped and space-distorted parts are relatively difficult in straightening $[17,18]$, that's why the straightening crack rate of the inner input shaft is higher than that of the output shaft. 


\subsection{Mechanism of straightening crack}

According to the straightening process theory, the part appear straightening cracks because the maximum stress of the part exceeds the tensile strength. Depending on the material and structure of the part, it can be divided into two types of fracture models, one is the ductile fracture model, and the other is brittle fracture model. The steel used in gear shafts is generally low-carbon alloy steel. The hardness after heat treatment is generally not more than 50HRC, showing good plastic deformation ability. In order to improve the contact strength, fatigue strength and wear resistance, while having good toughness, the gear shaft is usually subjected to surface carburizing heat treatment. After the heat treatment is completed, the surface of the parts is significantly hardened, while the toughness is also greatly decreased, but the base component is still maintains good toughness. Fig. 6 shows the straightening cracks of carburized parts. It can be seen that the cracks generate from the surface carburized hardened layer, extending from the surface to the inside, showing brittle fracture characteristics.

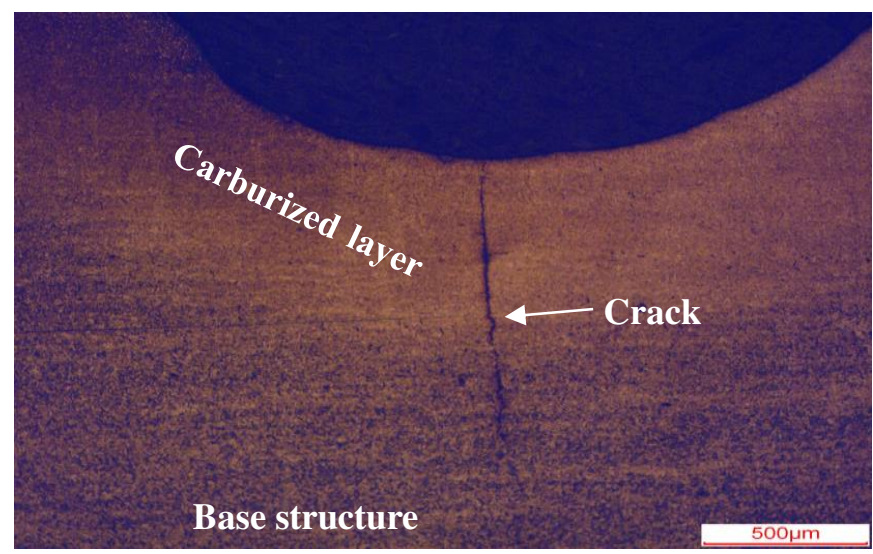

Fig. 6. Carburized gear shaft straightening crack

\subsection{Discussion on improvement of straightening crack}

For the straightening of carburized gear shaft parts, because the surface hardened layer has high tensile strength and is relatively brittle, while the base component performs plastic toughness, the straightening process mainly reduces the bending of the parts through the elastoplastic deformation of the base component. In order to avoid straightening cracks, it is necessary to complete the elastoplastic deformation of the base component before the maximum stress on the surface reaches the tensile strength. By consulting related data, researches and analyzing the straightening process, straightening crack improvements can be made mainly from the following aspects:

(1) Improvement of punch-anvil combination

For most of the small and medium-sized straightening machines which used to straighten the gear shaft, anvils are generally fixed on the workbench, so it is generally carried out by changing the position of the punch. According to the analysis of the pressure straightening mechanical model, it can be seen that even if the punch point is not at the maximum initial bending, the maximum deflection is also near the middle of two anvils. Therefore, when the stress concentration facts such as grooves and oil holes are just at the maximum bending point, other suitable punch point also can drive the reduction of the bending.

(2) Improvement of straightening program

The improvement of the straightening procedure include punch increments improvement and straightening strategy improvement. Regarding the selection of the punch increments, although it is based on the complex structure and the different properties of the surface and base materials after heat treatment, there is no mature algorithm and empirical formula for reference, but generally based on the consideration of straightening cracks, the increments cannot be too large, and based on the consideration of work hardening and cycle time, the increments cannot be too small. For the selection of the straightening strategy, data collection and analysis should be carried out on the straightening process. The punch points that are prone to straightening cracks should be reduced the number of straightening times as much as possible, and the bending be reduced by other punch point. In addition, the current advanced automatic straightening machine already has a vector straightening function. On the one hand, it can avoid the influence of stress concentration factors such as oil holes by accurately selecting the straightening angle, and on the other hand, it can be straightened by multiple angles, it will decompose the larger stress into several smaller stresses to reduce the maximum stress value during straightening [19].

(3) Improvement "straightening property" of parts

The "straightening property" refers to the ability of the bend part to be straightened without causing straightening crack. Because of the surface hardened part need to complete the elastoplastic deformation before the maximum stress of surface 
reaches the tensile strength, therefore, if the base structure of the part has good plasticity and low yield strength can be easily straightened without cracks. Generally the heat treatment process determines the "straightening property".

\section{Straightening process of gear shaft of automatic straightening machine}

The automatic straightening machine has been used more and more widely in the field of gear shaft straightening. The internal input shaft straightening of the dual-clutch transmission studied in this paper is carried out on the PAS/30 automatic straightening machine of GALDABINI Company as Fig. 7 shows. The straightening machine is a device that integrates automatic loading and unloading, parts identification, center hole cleaning, and online crack detection. Fig. 8 shows working status of internal input shaft straightening on PAS/30.

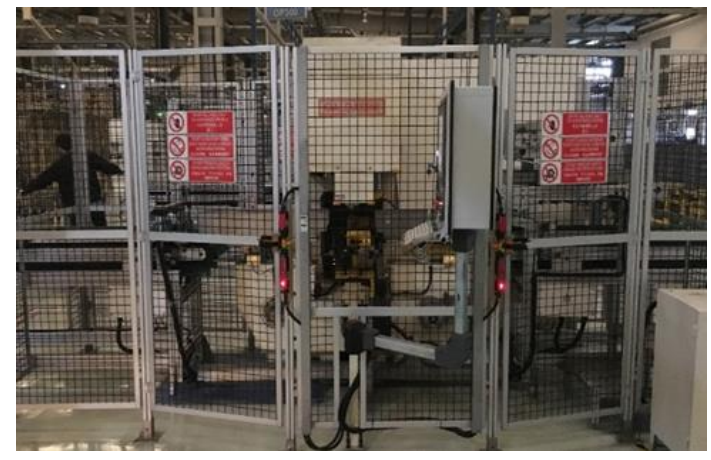

Fig. 7. GALDABINI- PAS/30 automatic straightening machine

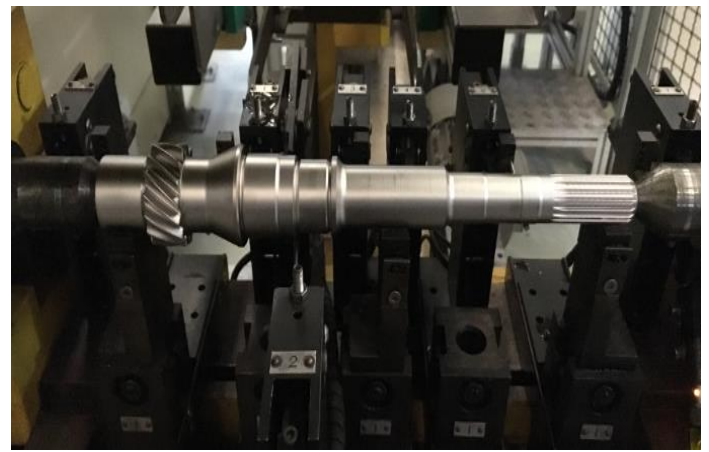

Fig. 8. Working status of internal input shaft straightening

\subsection{Main working system of PAS/30 automatic straightening machine}

\subsubsection{Curvature measurement system}

Fig. 9 shows the curvature measurement system model of PAS/30 automatic straightening machine. Sensors NO.1 and NO.5 are the reference, the values measured by the three sensors, NO. 2, NO. 3 and NO. 4 are used to obtain the deflection and the spatial azimuth angle of the three measurement points $\mathrm{A}, \mathrm{B}$ and $\mathrm{C}$ by least squares.

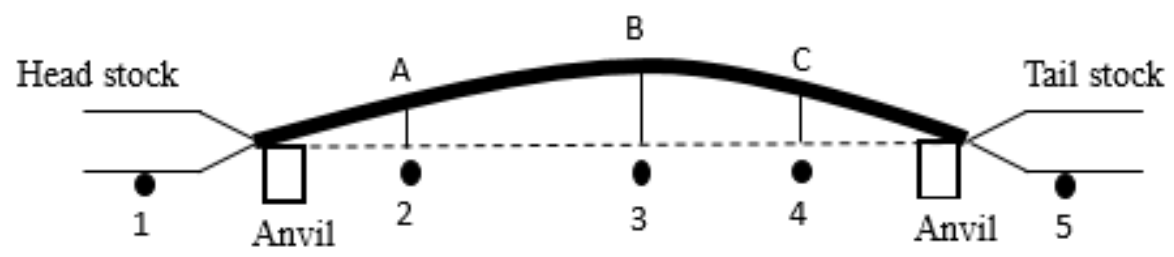

Fig. 9. Curvature measurements system of PAS/30 straightening machine

The equipment uses the TL410 contact sensor from METREL company, measuring range is $4 \mathrm{~mm}$ and measurement accuracy is $1 \mu \mathrm{m}$. The sensors collect once data every part rotates $1^{\circ}$. Therefore, a total of 360 data will be collected after the part rotates once. Fig. 10 shows the layout of TL410 for internal input shaft. The polar coordinate curve as Fig. 11 shows is calculated from the data and then deduce the deflection and the spatial azimuth.

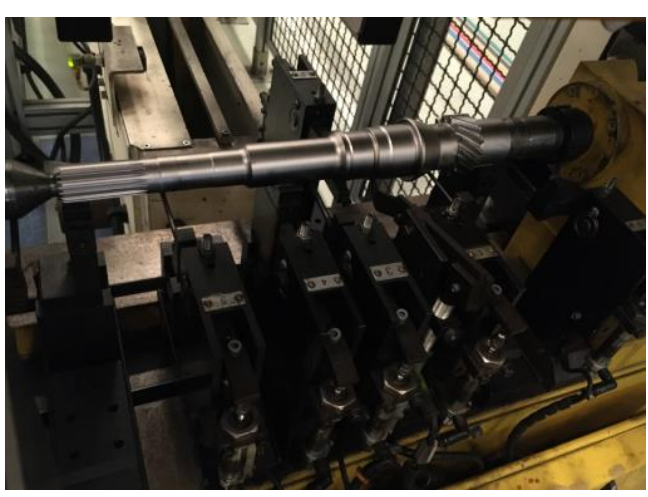

Fig. 10. Layout of TL410 sensors

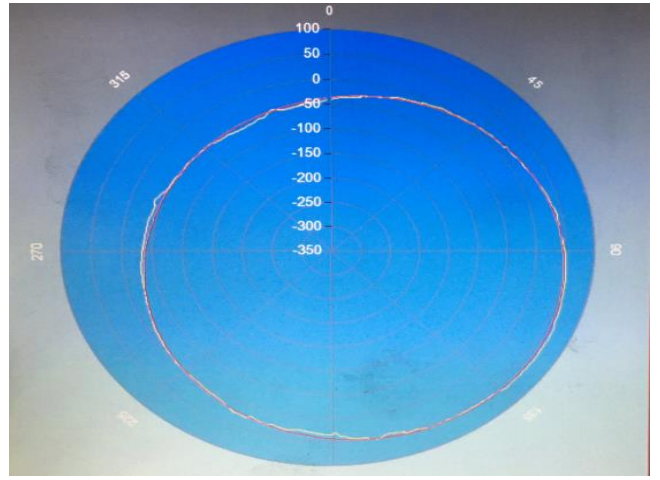

Fig. 11. Polar coordinate graph 


\subsubsection{Online crack detection system}

On-line crack detection technology based on acoustic emission not only makes online non-destructive testing of cracks a reality, but also has high efficiency, simple operation and good process stability, which have been widely used in the field of straightening [20]. PAS/30 type automatic straightening machine adopts the cis0.1 online crack detector which produced by QASS company to judge whether there are straightening cracks during the straightening process.

As shown in Fig. 12, cis0.1 online crack detector is mainly composed of host, preamplifier, piezoelectric sensor and so on. The piezoelectric sensor is coupled to the ram, and the ram directly contacts the surface of the part during straightening, when the crack generating, the elastic wave released and can be captured by the piezoelectric sensor, the preamplifier amplifies the signal captured by the piezoelectric sensor and transmits it to the host for data processing, recording and display.

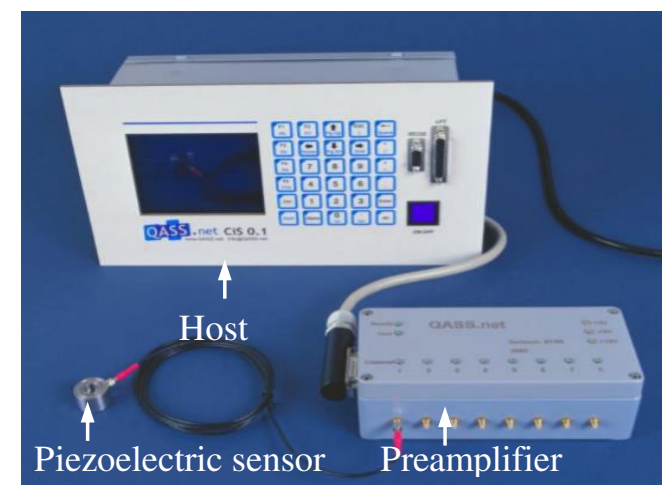

(a) Crack detector components

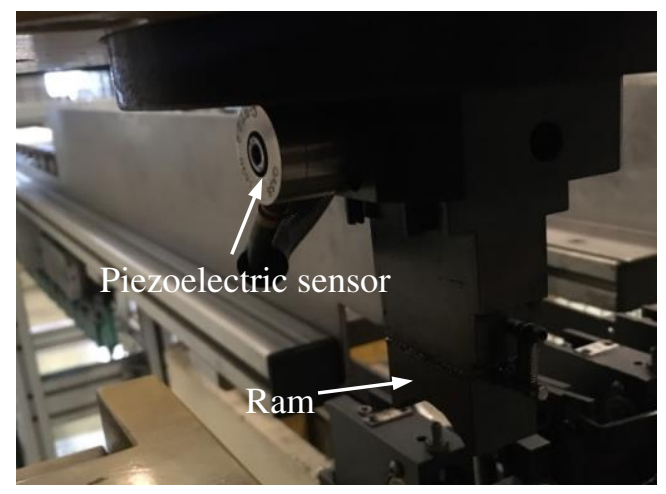

(b) Sensor location

Fig. 12. Crack detector components and sensor location

\subsection{Straightening program}

As shown in Fig. 13, due to the various deformation forms of the inner input shaft after heat treatment, the straightening adopts three anvils with three punch points. P1, P2 and P3 represent three punch point positions, S1, S2, and S3 represent three anvils position. When P1 is working, P1 , S1 and S2 form a three-point reverse bending straightening model; when the P5 is working, P5 , S2 and S3 form a three-point reverse bending straightening model; when the P3 is working, S2 will Automatically move down, out of contact with the shaft, so P3 ,S1 and S3 form a three-point recurve straightening model. M0, M1, M3, M5, and M7 represent five sensors position. Among them, M0 and M7 are reference sensors, cooperate with M1, M3, and M5 to measure the bending and azimuth angle. Finally, after the parts finish straightening, deflections of M1, M3 and M5 all need $\leqslant 0.03 \mathrm{~mm}$. According to status survey, it can be easy found that straightening cracks of internal input shaft are all generated at $\mathrm{P} 1$, and the crack positions are all at groove D.

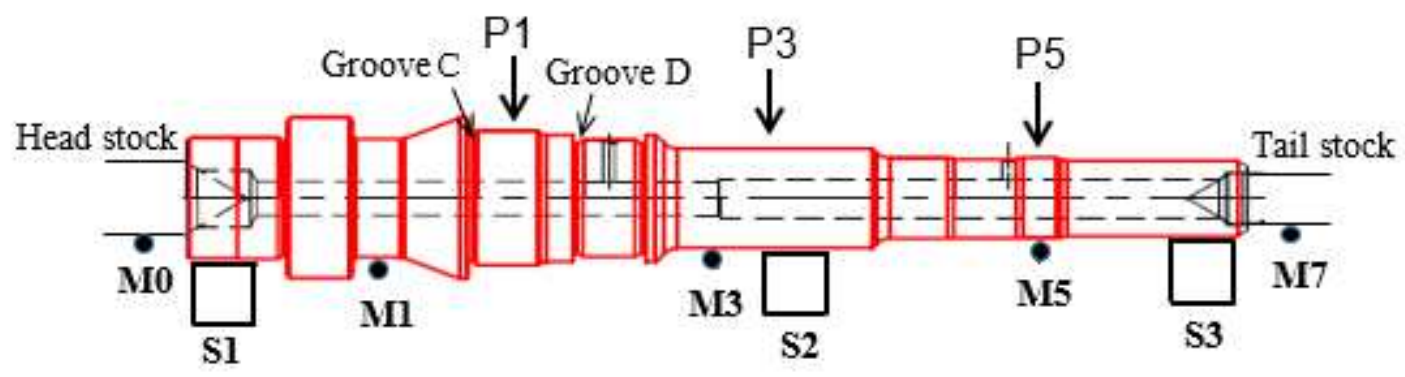

Fig. 13. Layout of internal input shaft straightening

Fig. 14 shows the current straightening process of internal input shaft. According to the magnitude of the deflection at different punch points, given an initial displacement for ram, each time the ram will increase a certain increment compared with the last time, usually with the deflection decreases and increments decreases accordingly as Fig. 15 shows until the program segment is finished. This method makes the ram gradually progresses by controlling the increment, and gradually increases the surface stress, which not only avoids the situation of over bending, but also effectively captures the maximum stress of the part between the yield strength and tensile strength so that can realize both part be straightened and crack avoidance. 


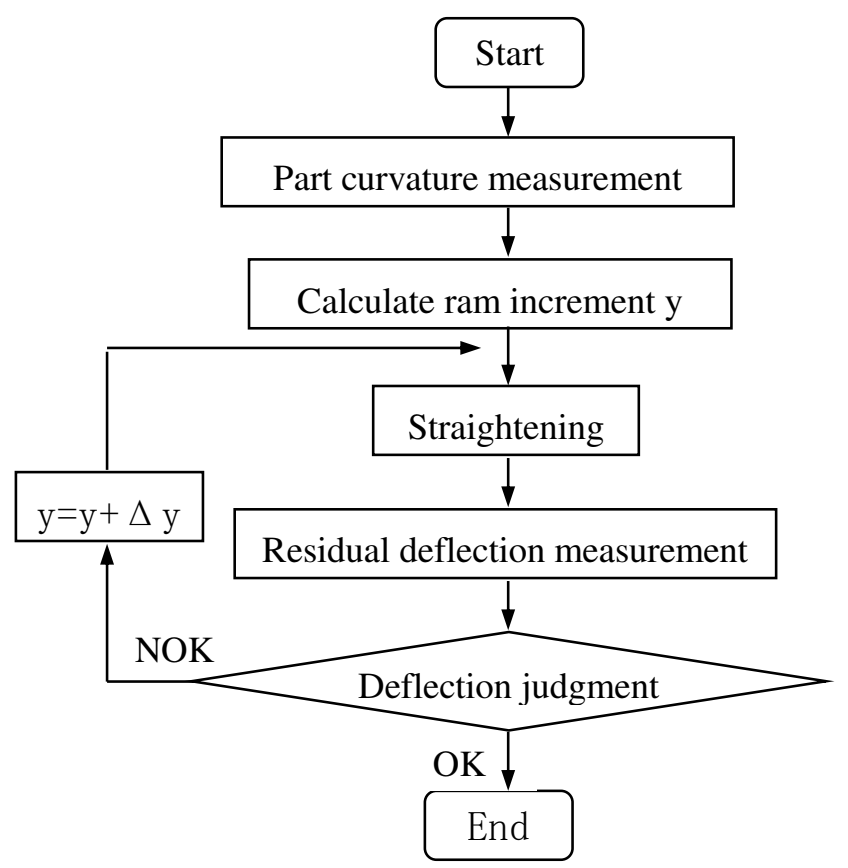

Fig. 14. Small-step progressive straightening process

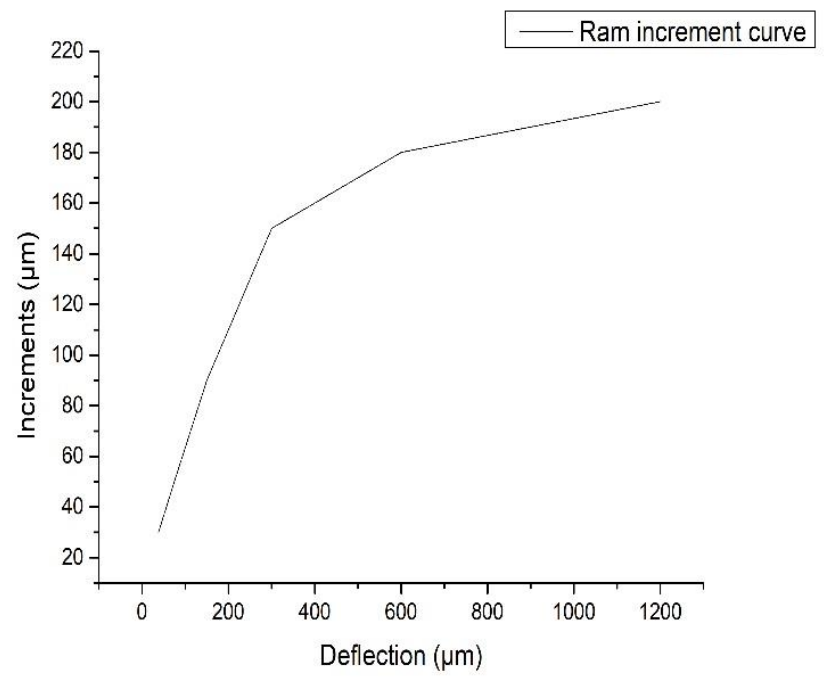

Fig. 15. Schematic diagram of ram increment $(\Delta y)$

\section{Methods of straightening crack improvement}

\subsection{Finite element analysis and improvement of the position of the punch point}

In view of the powerful analysis and simulation functions of finite element simulation software, more and more researches use finite element analysis software to guide the straightening process and achieve good results [21-24]. By simulating the stress state during the straightening process, it can provide strong support for the selection of punch position during straightening. This paper uses ANSYS finite element analysis software to analyze the internal input shaft in the straightening process and find the best punch position which the maximum stress value is the smallest.

\subsubsection{D model establishment}

Fig. 16 shows the 3D model of internal input shaft straightening. Due to the gears, splines and top hole top are not the impact factor, so it's simplified when drawing.

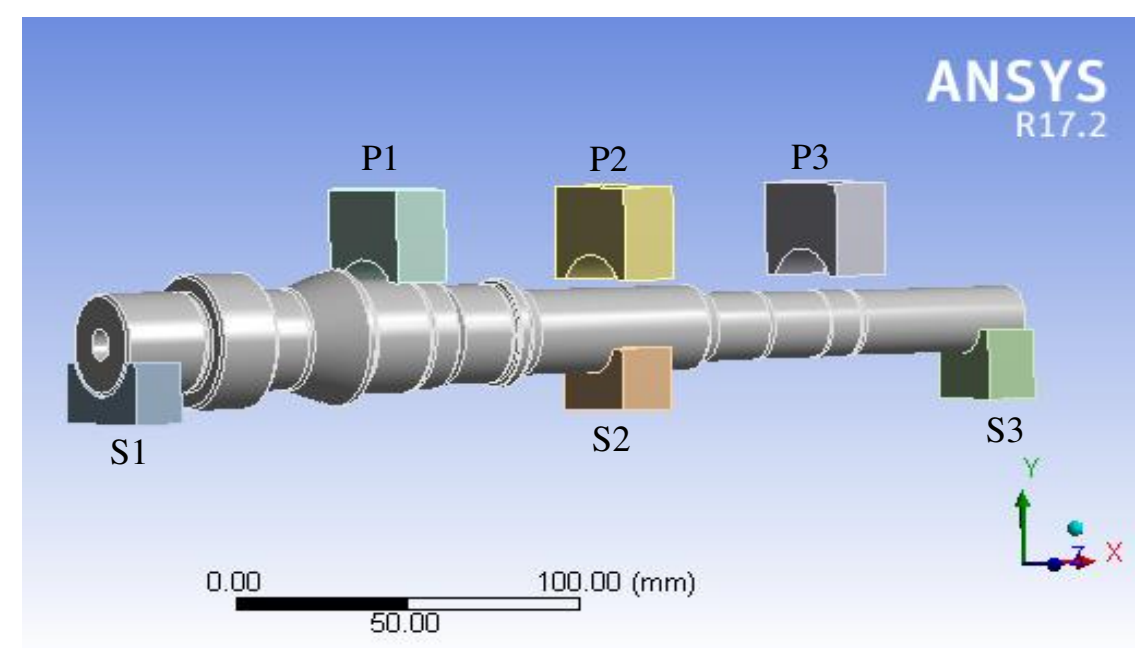

Fig. 16. 3D model of internal input shaft straightening

As shown in Fig. 17, since the straightening cracks are all generated at groove D during straight on P1. P1, S1, S2 form a three-point reverse bending straightening. Therefore, the simulation process focused on P1 process. 


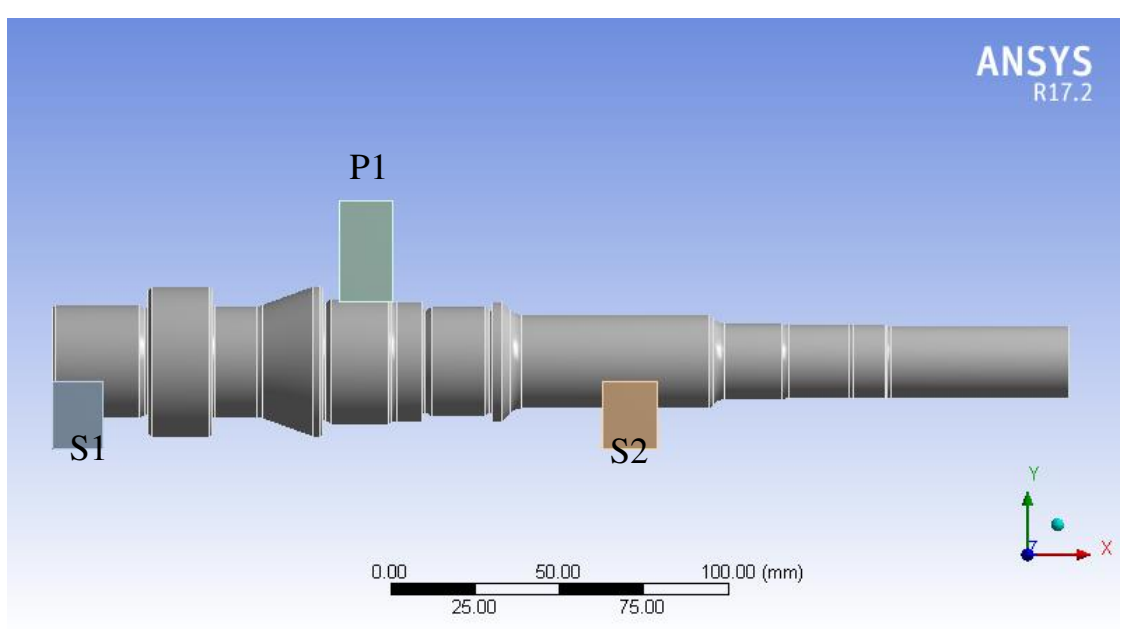

Fig. 17. 3D model of P1 process

\subsubsection{Analysis of stress magnitude at different punch points}

Fig. 18 shows according to the structure of the internal input shaft, there are three position options for the P1. Beside the current punch position (2), there are other two punch positions (1) and (3).

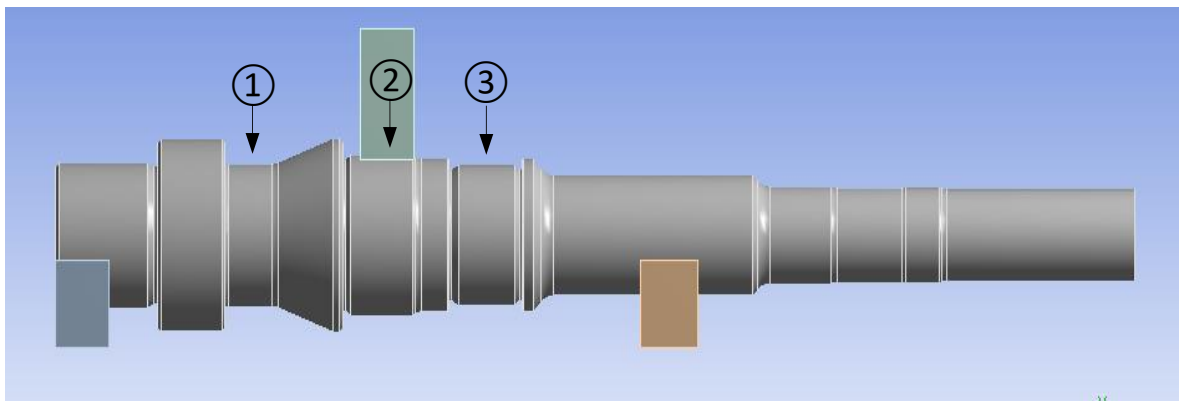

Fig. 18. $P 1$ point optional location distribution

Table 1 shows the maximum stress value for different P1 positon. It can be seen that when the P1 at the position (2), the maximum stress point is at the groove $\mathrm{D}$, which is consistent with actual crack position. When the P1 point is at the position (1), the stress is the smallest, so according to finite element simulation, it can be concluded that the position (1) is the best alignment point for the $\mathrm{P} 1$ point.

Table 1 Maximum stress and position distribution at each position of P1

\begin{tabular}{cccc}
\hline \multicolumn{2}{c}{ Table 1 Maximum stress and position distribution at each position of P1 } & \\
\hline P1 position & (1) & (2) & \\
\hline $\begin{array}{c}\text { Maximum tensile stress value } \\
(\mathrm{MPa})\end{array}$ & 236.14 & 398.8 & 425.55 \\
Maximum tensile stress positon & Groove $\mathrm{C}$ & GrooveD & Groove D \\
\hline
\end{tabular}

Fig. 19 shows the stress distribution when the punch at position (1). It can be see that the maximum stress position moved form groove $\mathrm{D}$ to groove $\mathrm{C}$. 


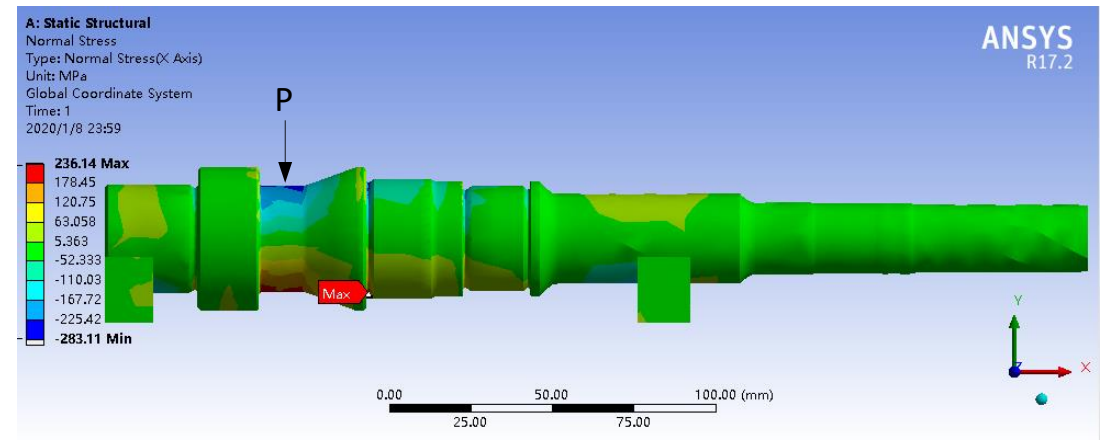

(a) Overall stress distribution

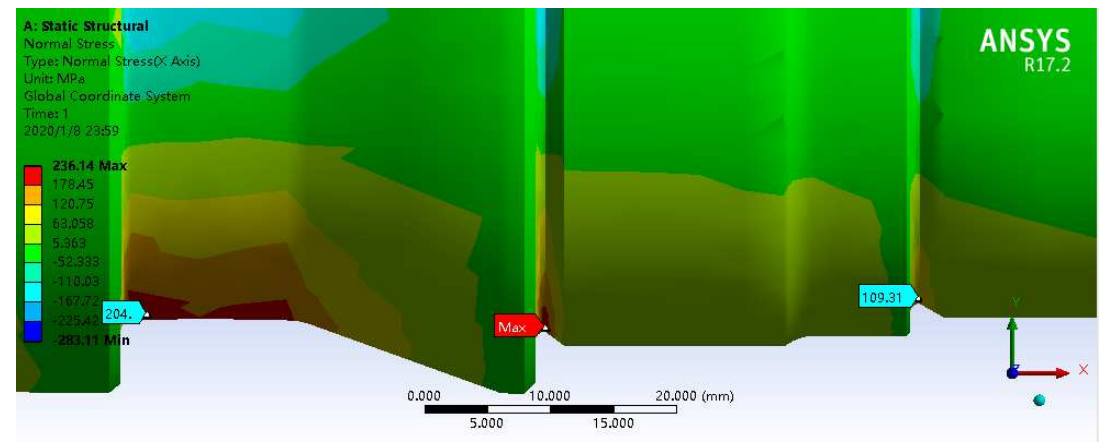

(b) Partial stress distribution

Fig. 19. Stress distribution state when $P 1$ at position (1)

\subsubsection{Experimental verification}

From the finite element simulation results of $\mathrm{P} 1$ point, it is known that the position point (1) is the best position of P1. So P1 was changed to position (1). A total of 2700 pieces in 15 loads were continuously straightened for verification. Finally a total of 38 rack pieces. The crack rate dropped from $1.95 \%$ to $1.41 \%$, and the crack position moved from groove $\mathrm{D}$ to groove $\mathrm{C}$, the crack position is consistent with the results of finite element simulation.

\subsection{Straightening process analysis and improvement}

\subsubsection{Increments analysis and improvement}

Fig. 20 shows the effectiveness of increment magnitude on straightening. It can be seen that when initial deflection of the three parts are approximately the same, the final straightness requires that the retained deflection value is within $30 \mu \mathrm{m}$. The test selects increments of $30 \mu \mathrm{m}, 60 \mu \mathrm{m}$ and $90 \mu \mathrm{m}$ separately. When increments is $30 \mu \mathrm{m}$, it straightened 18 times and the total increment is $540 \mu \mathrm{m}$. When increment is $60 \mu \mathrm{m}$, it straightened 8 times, the total increment is $480 \mu \mathrm{m}$, when increment is $90 \mu \mathrm{m}$, it only straightened 4 times, the total increment is $360 \mu \mathrm{m}$. None of the three parts generate cracks. Therefore, it can be conducted that in the range of no straightening cracks, increasing the increment can not only reduce the number of straightening times, but also reduce the total increments of ram. In addition, the slopes of the three curves all show a trend from large to small, which also reflects the work hardening impact in the straightening process, it will leads to increase in the yield strength, so that leads to a decrease in the deformation under the same increment. 


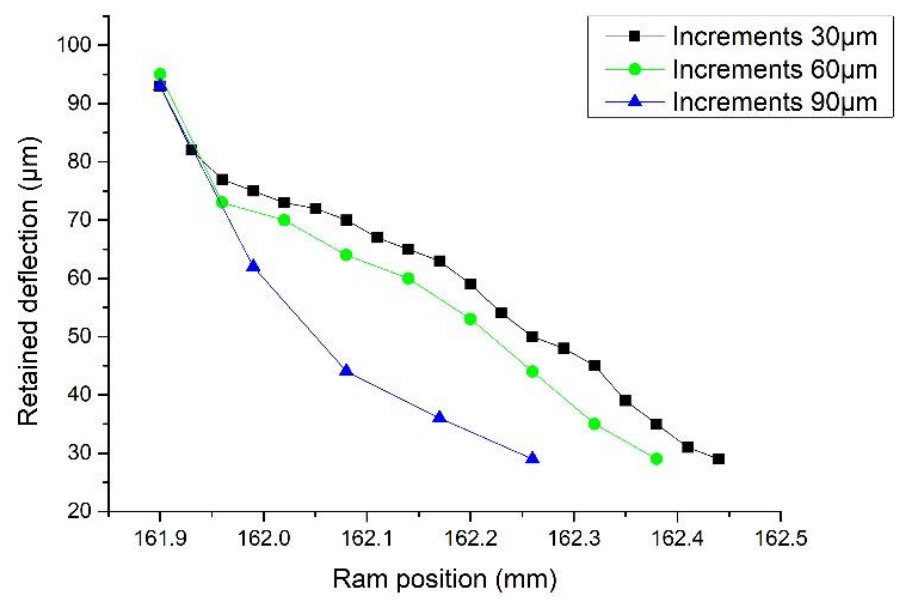

Fig. 20. Increment-retained deflection comparison

Since all cracks are generated when straightening at P1 position, and duo to the influence of work hardening straightening process, the ideal straightening process should reduce the number of straightening times as much as possible under the condition that the increments should not be too large to cause straightening cracks, this paper will reduce P1 straightening time from two aspect as follow:

(1) Decreasing the deflection of P3 drive the decrease of the deflection of P1. Since the distance between the P3 and the anvil is the longest, the bending moment that can be generated under the same load is the largest, so the parts are more prone to plastic deformation. From the actual straightening results, it can be seen that there is no straightening crack at this punch position, so the initial deflection of P1 to some extent can be reduced by the straightening of P3 if they have the same spatial azimuth. .

(2) Increase ram increment. From the relationship between increment and the retained deflection which is shown in Fig. 20 , it can be concluded that an appropriate increase in the ram increment can not only reduce the number of straightening times, but also reduce the total increment of the ram, thereby reducing the total displacements and finally reducing maximum stress on the part surface. Fig. 21 shows the comparison before and after the improvement of the incrementaldeflection curve of P1. P3 and P5 are also increased the increments to some extent.

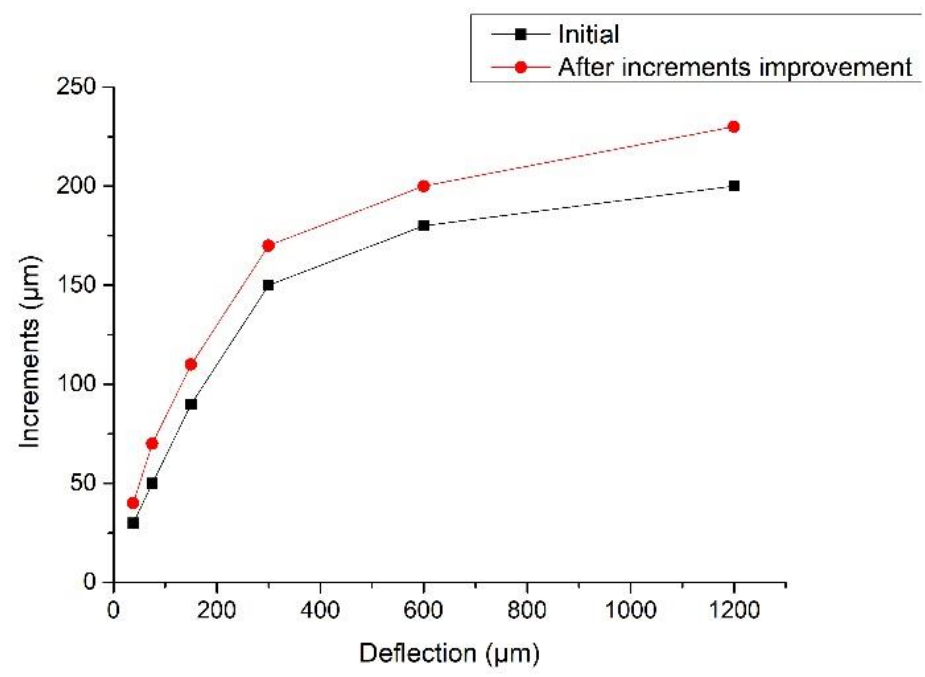

Fig. 21. Incremental comparison of $\mathrm{P} 1$ before and after improvement

\subsubsection{Vector straightening}

According to the discussion on the straightening crack before, vector straightening method can reduce the maximum stress by decomposition. Therefore, P1 adopt vector straightening method. As is shown in Fig. 22, in order to ensure that the straightened parts not only meet the requirements of the final straightness, but also avoid the distance between the 
maximum stress points after decomposition is too close, the conventional signal point pressure is divided into three points during straightening, the angle between the two points is set to $30^{\circ}$, and the punch sequence is $\mathrm{P} 1, \mathrm{P} 2, \mathrm{P} 3$.

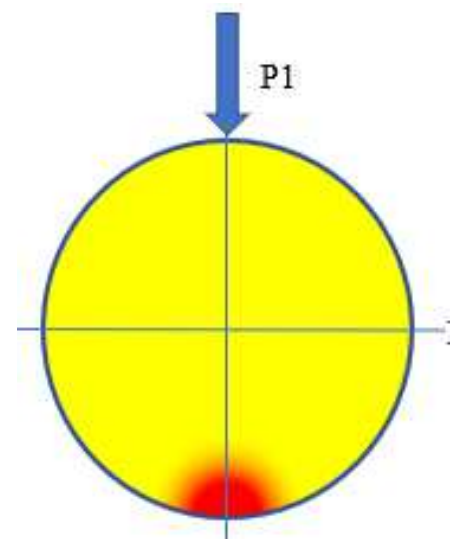

(a) Conventional straightening

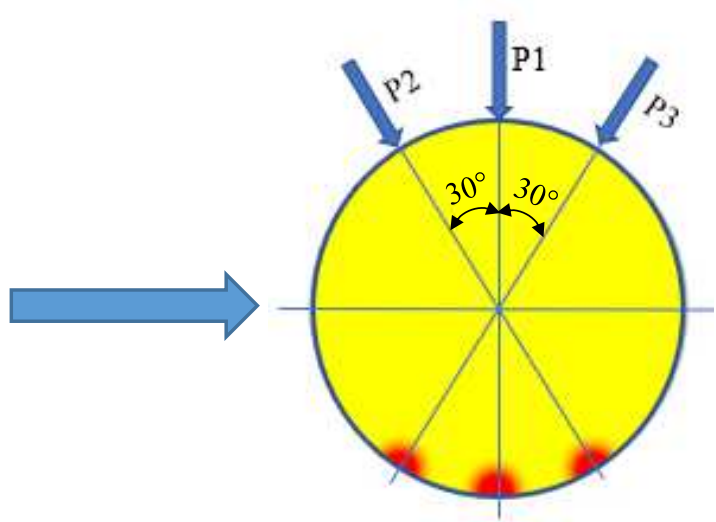

(b) Vector straightening

Fig. 22. Comparison of conventional straightening and vector straightening

\subsubsection{Experimental verification}

A total of 1800 pieces in 10 loads were continuously straightened for verification and a total of 19 crack pieces. Crack rate dropped from $1.41 \%$ to $1.05 \%$. When tracking and observing the straightening, it was also found that the decrease of the deflection of P3 obviously drive to decrease of the deflection of the P1. Straightening times on P1 is significantly reduced. In addition, due to the increase in the increment, the average cycle time is reduced from $48 \mathrm{~s}$ to $44 \mathrm{~s}$.

\subsection{Material properties analysis and improvement of heat treatment process}

According to the elastoplastic theory of part straightening, the mechanical properties of the material is one of the key factors for generating straightening cracks. Heat treatment is an indispensable step in the production process of gear shafts. It is also the most important process that affects the mechanical properties. A reasonable heat treatment process plays a very important role in improving the mechanical properties of parts materials.

\subsubsection{Heat treatment process}

Vacuum carburizing gas quenching continuous furnace from France ECM company is used for the internal input shaft. The furnace adopts pulse carburizing, the carburizing pressure is $10-15 \mathrm{mbar}$, the carburizing medium is acetylene, and the gas quenching medium is nitrogen.

The reaction formula of acetylene decomposition by Wei [25] is:

$$
\mathrm{C}_{2} \mathrm{H}_{2} \longrightarrow 2[\mathrm{C}]+\mathrm{H}_{2}+53.5 \mathrm{kcal}
$$

Heat treatment process : loading $\rightarrow$ preheating $\rightarrow$ heating 、 carburizing 、 diffusion $\rightarrow$ quenching $\rightarrow$ tempering

$$
\rightarrow \text { cooling } \rightarrow \text { unloading }
$$

Among the process, heating, carburizing and diffusion are all completed in heating cell. Fig. 23 shows heat treatment process of internal inputshaft, it can be seen that the preheating temperature is $380^{\circ} \mathrm{C}$ and time is $84 \mathrm{~min}$; the heating temperature is $970^{\circ} \mathrm{C}$ and total time in the heating cell is $135 \mathrm{~min}$; the gas quenching pressure is $13 \mathrm{bar}$ and time is $5 \mathrm{~min}$; the tempering temperature is $170^{\circ} \mathrm{C}$ and time is $168 \mathrm{~min}$; the air cooling time is $36 \mathrm{~min}$. Fig. 24 shows carburizing process, it can be seen that the total number of acetylene pulses for inner input shaft is 6 , the flow rate of each pulse is $3000 \mathrm{~L} / \mathrm{h}$, the total pulse time is $619 \mathrm{~s}$, and the rest of the time inject $1500 \mathrm{NL} / \mathrm{h}$ nitrogen for protection. Fig. 25 shows queching process, it can be seen that the gas quenching pressure is $13 \mathrm{bar}$ and the time is $5 \mathrm{~min}$. 


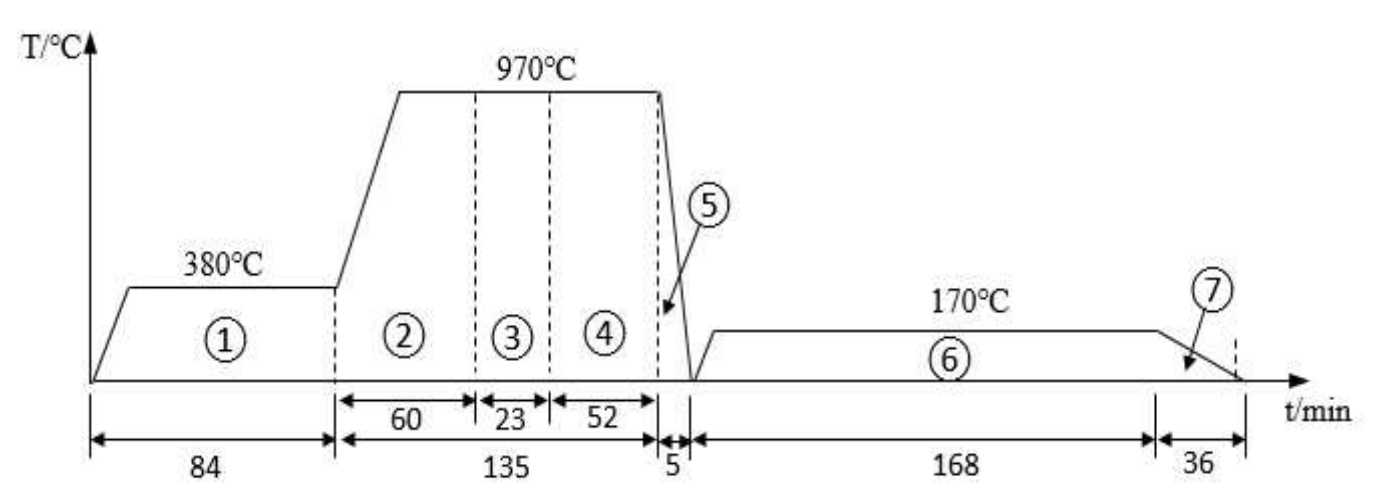

(1) Preheating

(2) Heating

(3) Carburizing

(4) Diffusion

(5) Quenching

(6) Tempering

(7) Cooling

Fig. 23. Temperature-time curve of heat-treatment process

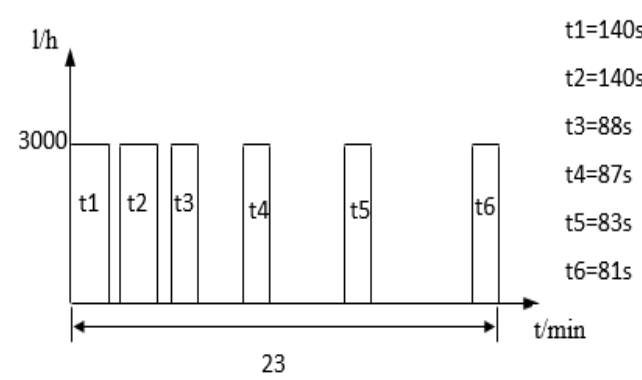

Fig. 24. Carburizing pulse

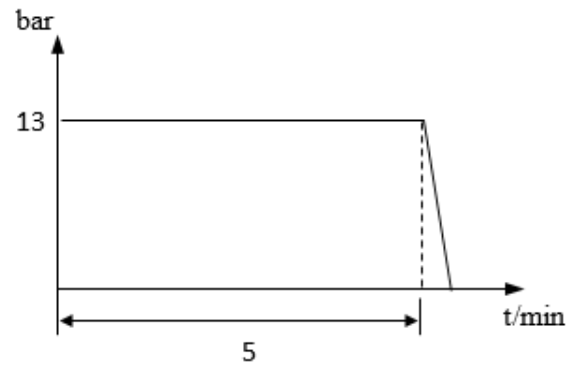

Fig. 25. Quenching process curve

\subsubsection{Heat treatment deformation state}

The process of heat treatment deformation is complicated, but the root cause of the deformation is the inconsistent structure transformation during heat treatment process and the different stresses generated by each component. Fig. 26 shows the parts loading station during teatment process.

Quenching temperature and quenching cooling rate are the two important factors that directly affect the structure transformation and heat treatment stress. They are the key parameters that affect the heat treatment deformation. For the gas quenched part, the gas quenching pressure determines the cooling rate. As shown in Fig. 27, three loads (labeled A, $\mathrm{B}$, and $\mathrm{C}$ respectively) are extracted for statistics on the deflection distribution. It can be seen that although the distribution of deflections is fluctuations to some extent, the overall are all normally distributed.

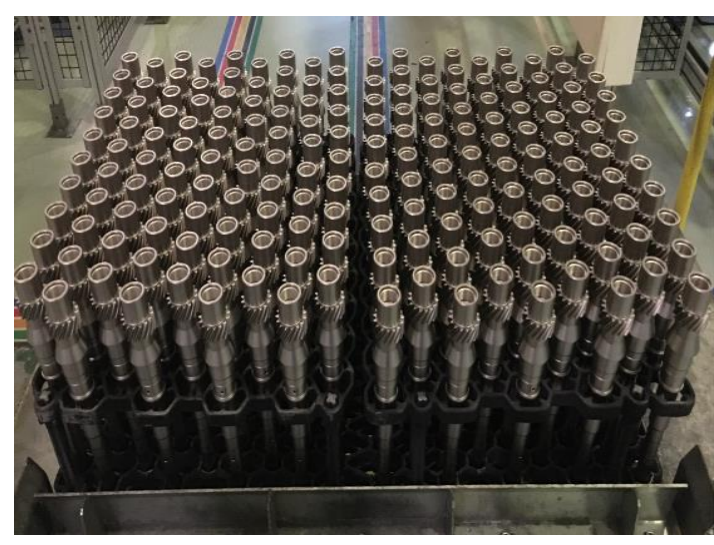

Fig. 26. Parts loading station

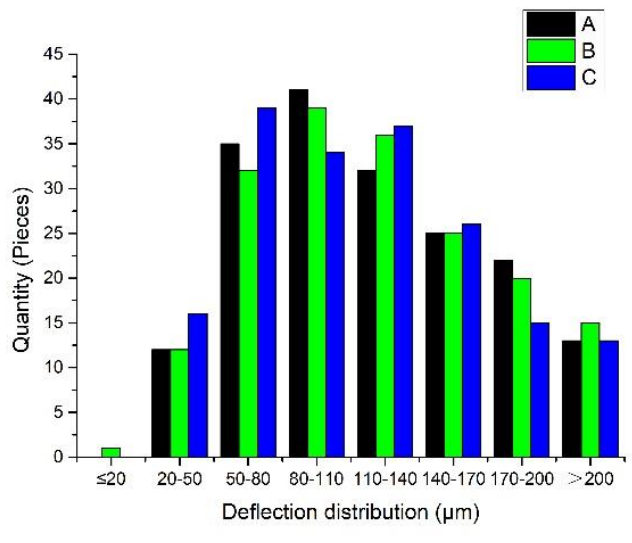

Fig. 27. Deflection distribute

\subsubsection{Tensile test}

In order to explore a reasonable heat treatment process, this paper combine the tensile test with the heat treatment test to analyze the mechanical properties under different gas quenching pressures in non-carburized state to simulate the changes 
in the mechanical properties of the base structure of normal carburized parts. Providing data support for obtaining reasonable gas quenching parameter. Fig. 28 shows the tensile sample and size.

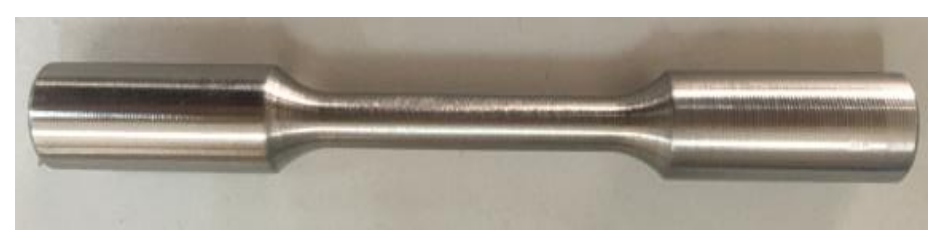

(a) Tensile sample

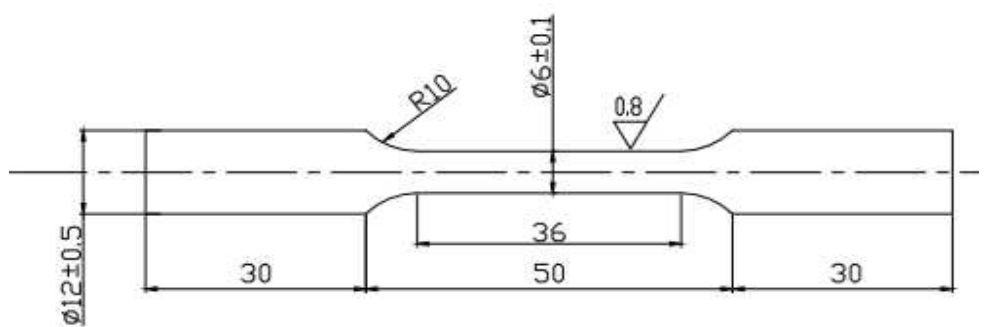

(b) Tensile sample size

Fig. 28. Tensile sample and size

The test also applied in ECM furnace. Sample is bound to the parts and heat treatment together. In order to obtain better gas quenching process parameters, gas quenching pressure test is expanded to both ends on the basis of original gas quenching pressure (13bar). At the same time, considering the size of the sample is smaller than parts, so the structure transformation speed is faster than part. Therefore, the gas quenching pressure is selected as 4bar, 7bar, 10bar, 13bar, and $16 \mathrm{bar}$ respectively. Samples are carried out on the tensile testing machine after heat treatment to compare the mechanical properties. After the tensile test is completed, quality conformities such as surface hardness, core hardness, microstructure and so on are also implemented.

Table 2 shows the results of sample tensile test with different gas quenching pressures. It can be seen that reducing the gas quenching pressure not only significantly reduces the yield strength and tensile strength, but also effectively reduces the yield-tensile ratio, thereby expanding the space for plastic deformation.

Table 2 Tensile test results of samples with different gas quenching pressures

\begin{tabular}{cccccc}
\hline Items & 4bar & 7 bar & 10 bar & 13 bar & 16 bar \\
\hline $\begin{array}{c}\text { Yield strength } \\
(\mathrm{MPa})\end{array}$ & 719 & 784 & 970 & 1179 & 1277 \\
$\begin{array}{c}\text { Tensile strength } \\
(\mathrm{MPa})\end{array}$ & 1016 & 1080 & 1231 & 1469 & 1577 \\
$\begin{array}{c}\text { Yield-Tensile ratio } \\
\text { Young's modulus }\end{array}$ & 0.708 & 0.726 & 0.788 & 0.802 & 0.810 \\
$(\mathrm{GPa})$ & 359 & 373 & 422 & 491 & 511 \\
\hline
\end{tabular}

Table 3. shows quality conformity result. It can be see from the table that as the gas quenching pressure decreases, the surface hardness no significant changes but the core hardness obviously decrease. When the gas quenching pressure is $7 \mathrm{bar}$, the core hardness is within the lower range, and other quality inspection indicators are all meet the requirements, so it's the best option among the 5 gas quenching pressure options.

Table 3 Quality inspect results of samples with different gas quenching pressures

\begin{tabular}{ccccccc}
\hline Items & Requirement & 4 bar & 7 bar & 10 bar & 13 bar & 16 bar \\
\hline Surface hardness (HRC) & $59-63$ & 58.5 & 59.9 & 61.3 & 61.9 & 62.4 \\
Core hardness (HV) & $370-500$ & 320 & 372 & 421 & 455 & 486 \\
Case depth (mm) & $0.55-0.75$ & 0.53 & 0.59 & 0.62 & 0.63 & 0.62 \\
& Martensite level 1-4 & 3 & 4 & 4 & 4 & 4 \\
Microstructure & Retained austenite level 1-4 & 3 & 3 & 3 & 3 & 3 \\
& Carbide level 1-3 & 1 & 1 & 1 & 1 & 1 \\
& Ferrite level 1-3 & 3 & 1 & 1 & 1 & 1 \\
\hline
\end{tabular}




\subsubsection{Improvement of heat treatment}

It can be concluded from the tensile test that reducing the core hardness can effectively reduce the yield strength and yield-tensile ratio, so that provide more space for plastic deformation during straightening, thereby helping to reduce the generation of straightening cracks. Therefore, it is an ideal choice to control the core hardness in lower limit range. From the metallographic inspection results it can be concluded that when the gas quenching pressure is 7 bar, the core hardness is lower limit range, but because the internal input shaft is thicker than the sample, The heat capacity is larger when fully loaded, so a stronger cooling rate is required to make it have a hardness equivalent to the sample. Therefore, the internal input shaft is tested with $7 \mathrm{bar}$ and $9 \mathrm{bar}$, and for each test, 4 parts were taken from different locations for quality inspection. As Table 4 shows. According to the table, it can be seen that when pressure is $9 \mathrm{bar}$, the core hardness is lower limit range, and the other quality inspection results are within the qualified range, so $9 \mathrm{bar}$ can be selected as the gas quenching pressure parameter.

Table 4 Gas quenching quality test results of the internal input shaft

\begin{tabular}{|c|c|c|c|c|c|c|c|c|c|}
\hline \multirow{4}{*}{ Items } & \multirow{4}{*}{ Requirement } & \multicolumn{8}{|c|}{ Quenching pressure } \\
\hline & & \multirow{2}{*}{\multicolumn{4}{|c|}{$\begin{array}{c}\text { 7bar } \\
\text { location }\end{array}$}} & \multirow{2}{*}{\multicolumn{4}{|c|}{$\begin{array}{c}\text { 9bar } \\
\text { location }\end{array}$}} \\
\hline & & & & & & & & & \\
\hline & & $1 \#$ & $2 \#$ & $3 \#$ & 4\# & 1\# & $2 \#$ & $3 \#$ & 4\# \\
\hline $\begin{array}{c}\text { Surface hardness } \\
(\text { HRC })\end{array}$ & $59-63$ & 61.0 & 59.6 & 60.2 & 61.4 & 61.3 & 62.6 & 61.8 & 59.8 \\
\hline Core hardness (HV) & $370-500$ & 361 & 356 & 344 & 352 & 386 & 398 & 402 & 379 \\
\hline Case depth $(\mathrm{mm})$ & $0.55-0.75$ & 0.60 & 0.62 & 0.59 & 0.60 & 0.62 & 0.62 & 0.64 & 0.61 \\
\hline \multirow{4}{*}{ Microstructure } & Martensite level 1-4 & 4 & 4 & 4 & 4 & 4 & 4 & 4 & 4 \\
\hline & $\begin{array}{c}\text { Retained austenite } \\
\text { level 1-4 }\end{array}$ & 3 & 3 & 3 & 3 & 3 & 3 & 3 & 3 \\
\hline & Carbide level 1-3 & 1 & 1 & 1 & 1 & 1 & 1 & 1 & 1 \\
\hline & Ferrite level 1-3 & 1 & 1 & 1 & 1 & 1 & 1 & 1 & 1 \\
\hline
\end{tabular}

This paper compares 3 loads (540 pieces) of the deflection of the parts before and after the gas quenching pressure is changed. As Fig. 29 shows, deflection of parts is significantly reduced also, and the average value decreased from $118.2 \mu \mathrm{m}$ to $92.6 \mu \mathrm{m}$.

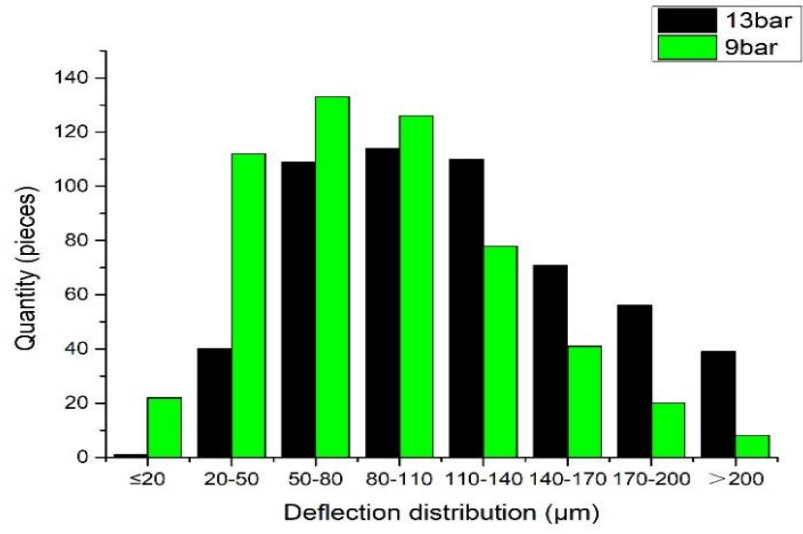

Fig. 29. Deflection distribution of parts under different gas quenching pressures

It can be concluded from Fig. 29 that reducing the gas quenching pressure can not only reduce the core hardness, but also reduce the deflection, thereby reducing the possibility of straightening cracks advanced.

Due to the reduction of core hardness and yield-tensile ratio, the plasticity and toughness of the part are enhanced, theoretically it can improve "straighten properties". As shown in Table 5, this paper compares the changes in the straightening performance of the parts before and after the heat treatment process is improved by the way of progressively increasing the ram until generate crack at point $\mathrm{P} 1$. 
Table 5 Comparison of "straightening property" before and after heat quenching pressure improvement

\begin{tabular}{|c|c|c|c|c|}
\hline $\begin{array}{l}\text { Quenching pressure } \\
\text { (bar) }\end{array}$ & $\begin{array}{l}\text { Initial deflection } \\
\qquad(\mu \mathrm{m})\end{array}$ & $\begin{array}{l}\text { Ram displacements } \\
(\mu \mathrm{m})\end{array}$ & $\begin{array}{l}\text { Retain deflection } \\
(\mu \mathrm{m})\end{array}$ & $\begin{array}{c}\text { Core hardness } \\
(\mathrm{HV})\end{array}$ \\
\hline \multirow{3}{*}{ 13bar } & \multirow{3}{*}{265} & 300 & 198 & \multirow{3}{*}{462} \\
\hline & & 400 & 104 & \\
\hline & & 500 & crack & \\
\hline \multirow{6}{*}{9 bar } & \multirow{6}{*}{267} & 300 & 145 & \multirow{6}{*}{385} \\
\hline & & 400 & 75 & \\
\hline & & 500 & 44 & \\
\hline & & 600 & 33 & \\
\hline & & 700 & 27 & \\
\hline & & 800 & crack & \\
\hline
\end{tabular}

It can be seen from Table 5 that after the heat treatment gas quenching process is improved, due to the decrease of the core hardness and the enhancement of the plasticity and toughness of the parts, the displacement and increment of the ram can be greatly increased. Fig. 30 shows the comparison of P1 increment after heat treatment is improved, it can be seen that the increments has been greatly increased again.

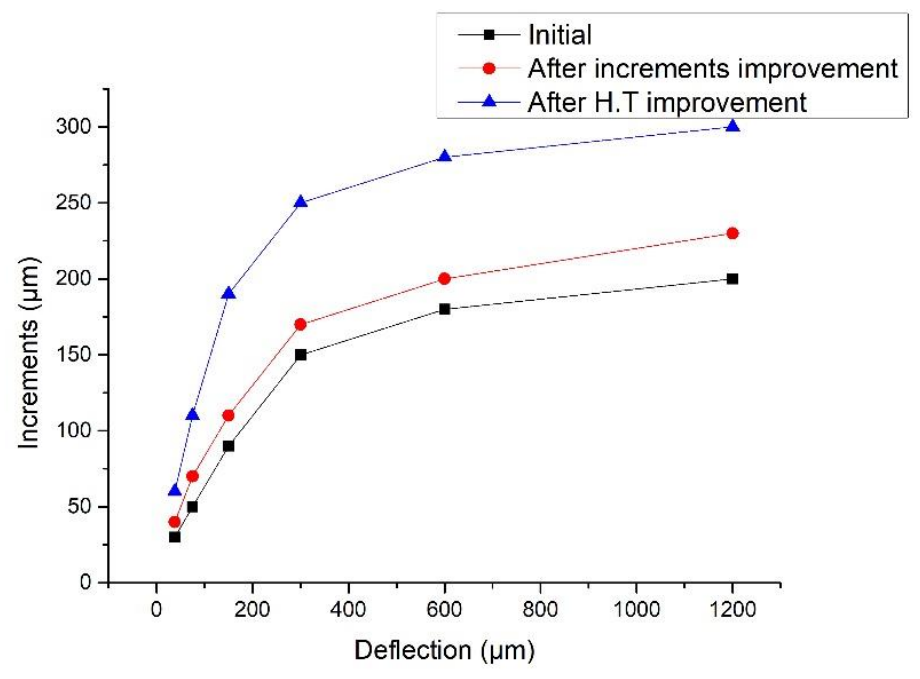

Fig. 30. Incremental comparison of $P 1$ before and after improvement

\subsubsection{Experimental verification}

A total of 3600 pieces in 20 loads were continuously tracked after quenching pressure changes from 13 bar to 9 bar, finally 5 crack pieces. Crack rate dropped from $1.05 \%$ to $0.14 \%$. When observation the straightening process after improvement, it was found that the straightening performance of the parts has been significantly improved. In addition, due to the large increase in the increment, the straightening process was significantly accelerated, so the average cycle time was reduced from $44 \mathrm{~s}$ to $35 \mathrm{~s}$.

\section{Conclusion}

As shown in Fig. 31, after improving P1 position, straightening process and heat treatment process, not only the straightening crack rate has been reduced from $1.95 \%$ to $0.14 \%$, but also due to increase the increments, the cycle time has also been reduced from 48 s to 35 s, thereby the production capacity has been increased by about $27 \%$ while reducing the scrap of parts. 


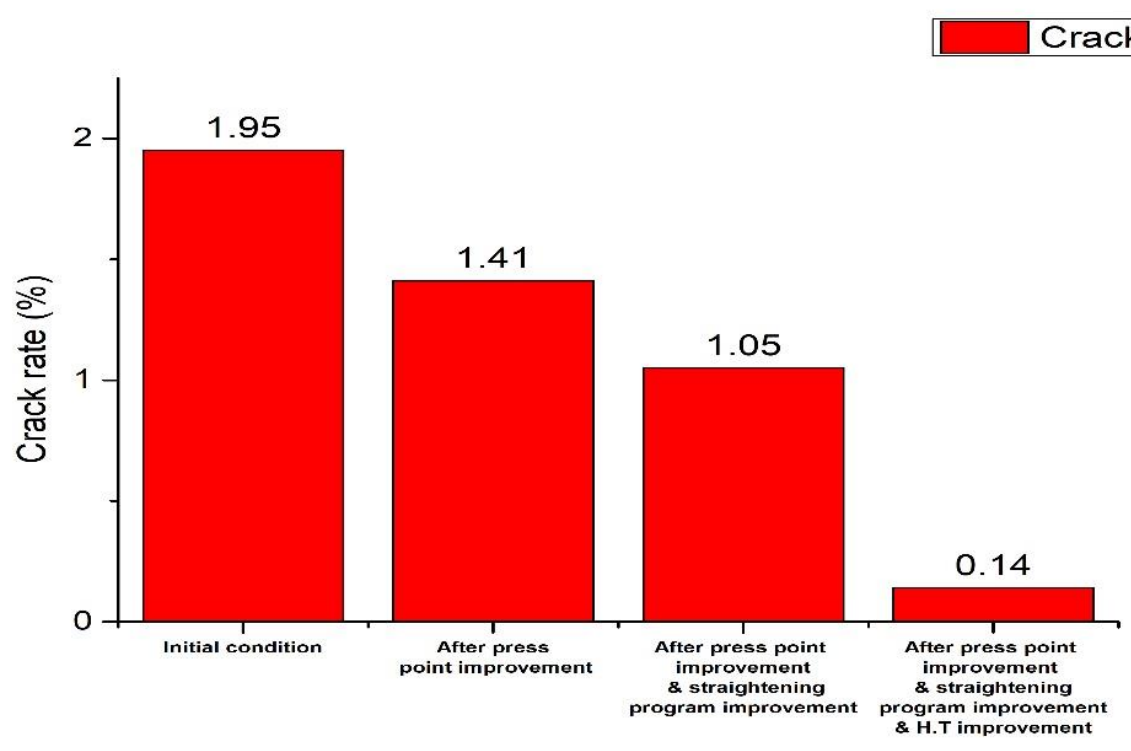

Fig. 31. Straightening crack rate comparison after improvement measures

The following conclusions can be drawn through the research of this paper:

(1)Stress comparison at different positions by finite element simulation are consistent with the actual straightening results. It verifies that finite element simulation has guiding significance for the selection of the straightening pressure point position.

(2)Times of straightening will lead to work hardening. A reasonable straightening process can effectively reduce the straightening crack rate by improving the straightening strategy, appropriately increase increments and adopting the vector straightening method for the pressure points that are prone to cracks.

(3)Core hardness of the part has an important influence on the "straightening property", while gas quenching pressure is the key parameter that determines the core hardness. Lowering the gas quenching pressure can effectively reduce the core hardness, thereby reducing the yield strength and yield-tensile ratio which can significantly reduce the straightening crack rate.

\section{Authors' contribution statement}

Wenzhen Ma: Investigation, Methodology, Data curation, Validation, Writing. Hongyao Shen: Supervision, review Guanhua Xu: Supervision.

\section{Acknowledgments}

This work was financially supported by the National Nature Science Foundation of China (No. 51975518, 51805477), the Science Fund for Creative Research Groups of National Natural Science Foundation of China (No. 51821093), Ningbo Science and Technology Plan Project (2019B10072), and the Fundamental Research Funds for the Central Universities (No. 2019QNA4004).

\section{References}

[1] Stelson KA, Gossard D C.(1982) An adaptive press brake control using an elastic-plastic material model. J Eng Ind-trans ASME104(4):389-393.

[2] Stelson KA.(1983) Real-time identification of workpiece material characteristics from measurements during brakeforming. J Eng Indtrans ASME,105(1):45-53.

[3] Stelson K A.(1986) An adaptive press brake control for strain-hardening materials. J Eng Ind 108(2):127-132.

[4] Talukder N, Singh A N. (1991) Mechanics of bar straightening.1. General-analysis of straightening process. J Eng Ind-trans ASME 113(2):224-227.

[5] Katoh T, Urata E, Nakanishi M, et al. (1991) Control for straightening process of seamless pipes. JSME Int J Ser III-Vibration Control Eng Ind 34(3):427-432.

[6] Katoh T, Urata E.(1993) Measurement and control of a straightening process for seamless pipes. J Eng Ind 115(3):347-351. 
[7] Murata M, Kuboki T, Takahashi K. (2008) Effect of hardening exponent on tube bending. J Materials Processing Technol 201(1-3):189192.

[8] Eggertsen PA, Mattiasson K. (2009) On the modelling of the bending-unbending behavior for accurate spring back predictions. Int J Mech Sci 51(7):547-563.

[9] Megharbel A, Nasser GA, Domiaty A. (2008) Bending of tube and section made of strain-hardening materials. J Mat Pro Tech 203(13):372-380.

[10] Schleinzer G, Fischer FD. (2000) Residual stresses in new rails. Mat Sci Eng 288(2):280-283.

[11] Schleinzer G, Fischer FD. (2001) Residual stresses formation during the roller straightening of railway rails. Int J Mech Sci 43(10):22812295.

[12] Kim SC, Chung SC. (2002) Synthesis of the multi-step straightness control system for shaft straightening processes. Mechatronics 12(1): 139-156.

[13] Kim SC, Chung SC. (1999) Synthesis of a geometric adaptive straightness control system for shaft straightening. A Manuf Res Conf 27:269-274.

[14] Zhai H. (2003) Research on straightening technology CAM system. J Mech Eng 16(2):175-177.

[15] Zhao K M. (2002) Finite element analysis of the three-point bending of sheet metals. J Mat Pro Technol 122(1): 6-11.

[16] Fujimaki K, Mitsui K. (2007) Radial error measuring device based on auto-collimation for miniature ultra-high-speed spindles. Int J Mach \& Manuf 47(11):1677-1685.

[17] Zhai H. (2004) Research on shaft parts straightening technology general predictive multi-steps algorithm. J Plasticity eng 11:50-53.

[18] Zhai H.(2002) Research of Roller Straightening theory and experiment. J Textile Res 23:68-69.

[19] Kirsch DI, Bister DI, Schweizer D M.(2013) Gear grinding machine makes angle between straight line of axis of rotation of straightening roller and vector of straightening direction of straightening roller.

[20] Ismonov S, Daniewicz S R. (2012) Study of an on-line crack compliance technique for residual stress measurement using 2D finite Element Simulations of Fatigue Crack Growth Conf

[21] Zhang Z. (2019) Finite element simulation study on residual cross-sectional opalization of thin-walled circular steel tubes in continuous rotary straightening process. Int J Adv Manuf Technol 102(5-8):2633-2647.

[22] Yu S, Long M, Wang Q, et al. (2019) Effect of the strand corner structure on the corner stress during the bending and straightening processes in slab continuous casting. J Manuf Pro 48:270-282.

[23] Li S, Wei C, Long Y.(2020) Deformation analysis of engineering reinforcement straightening based on bauschinger effect. Int J Ste Struct 20(1):1-12.

[24] Ma L, Du Y, Meng Z, et al.(2020) Effect of process parameters on steel tube roundness in straightening process. J Iron \& Steel Res Int 27(11):1270-1283.

[25] Wei S, Wang G, Zhao X. (2014) Experimental study on vacuum carburizing process for low-carbon alloy steel. J Mat Eng \& Perf 23(2):545-550. 
Figures

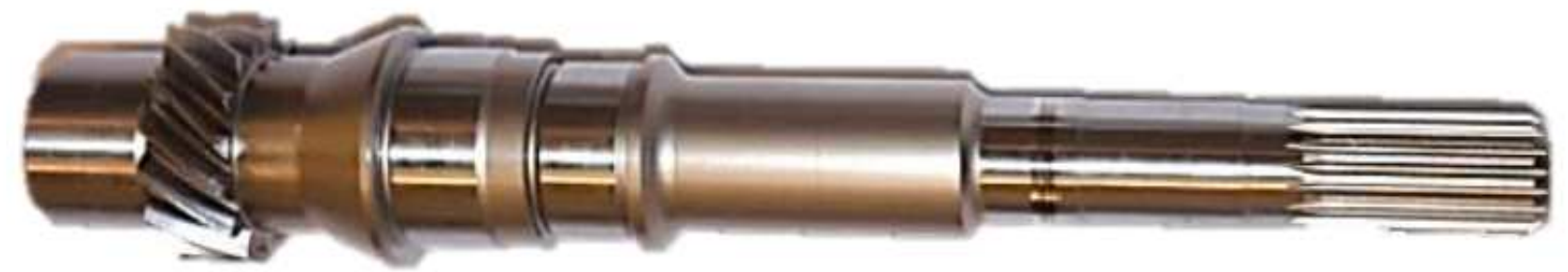

Figure 1

Internal input shaft

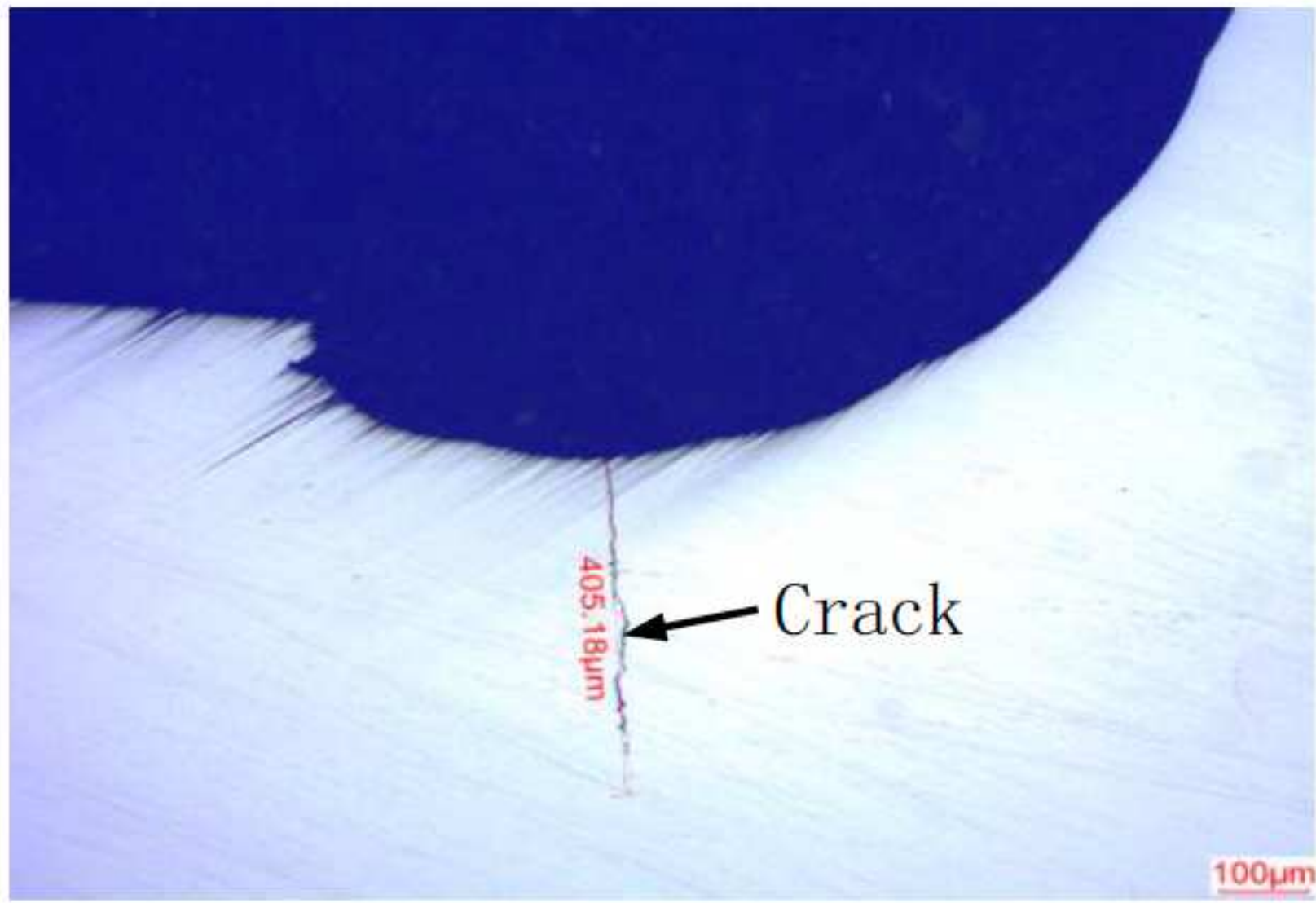

Figure 2 
Straightening crack

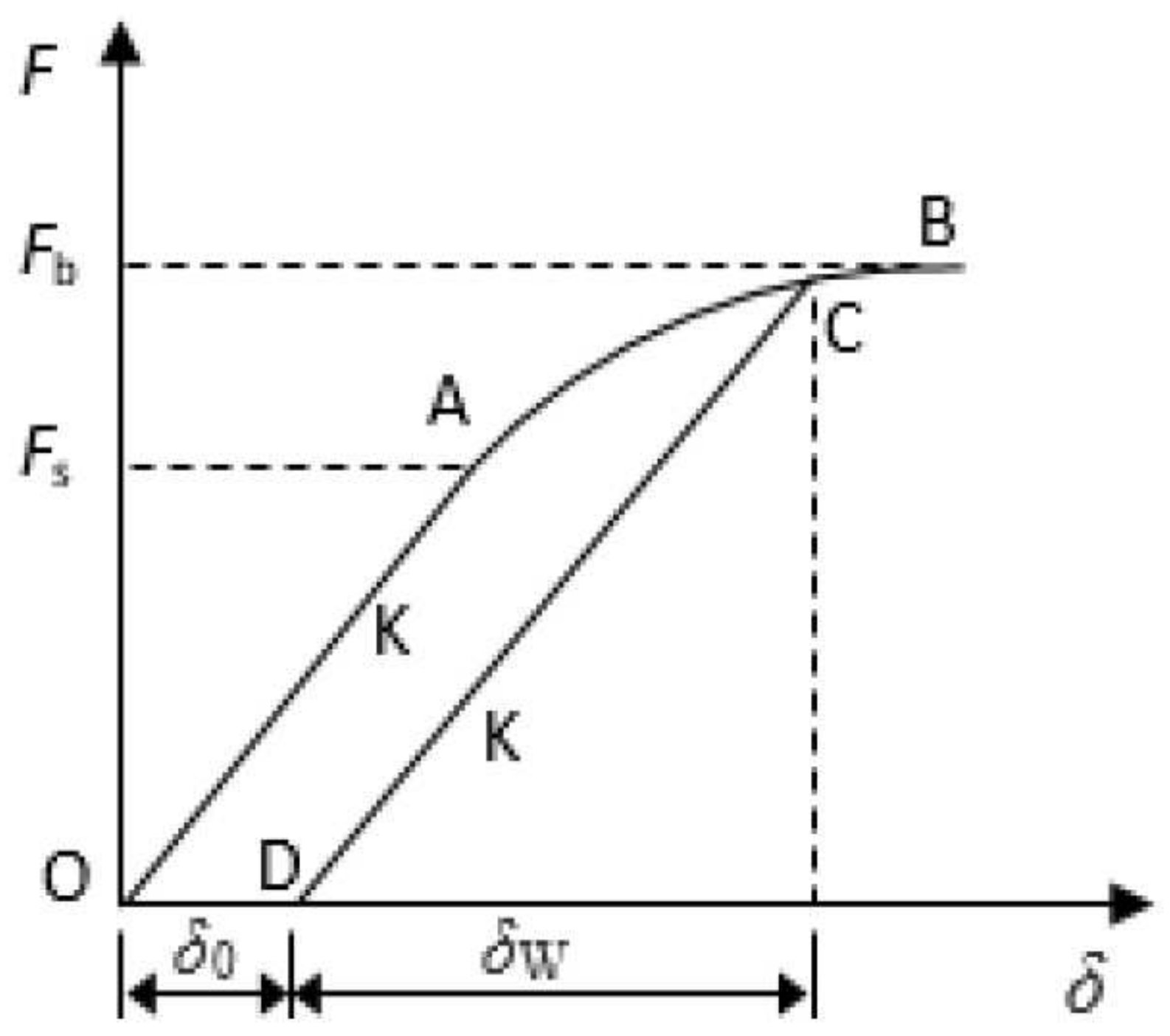

Figure 3

Elastoplastic pressure straightening process model 


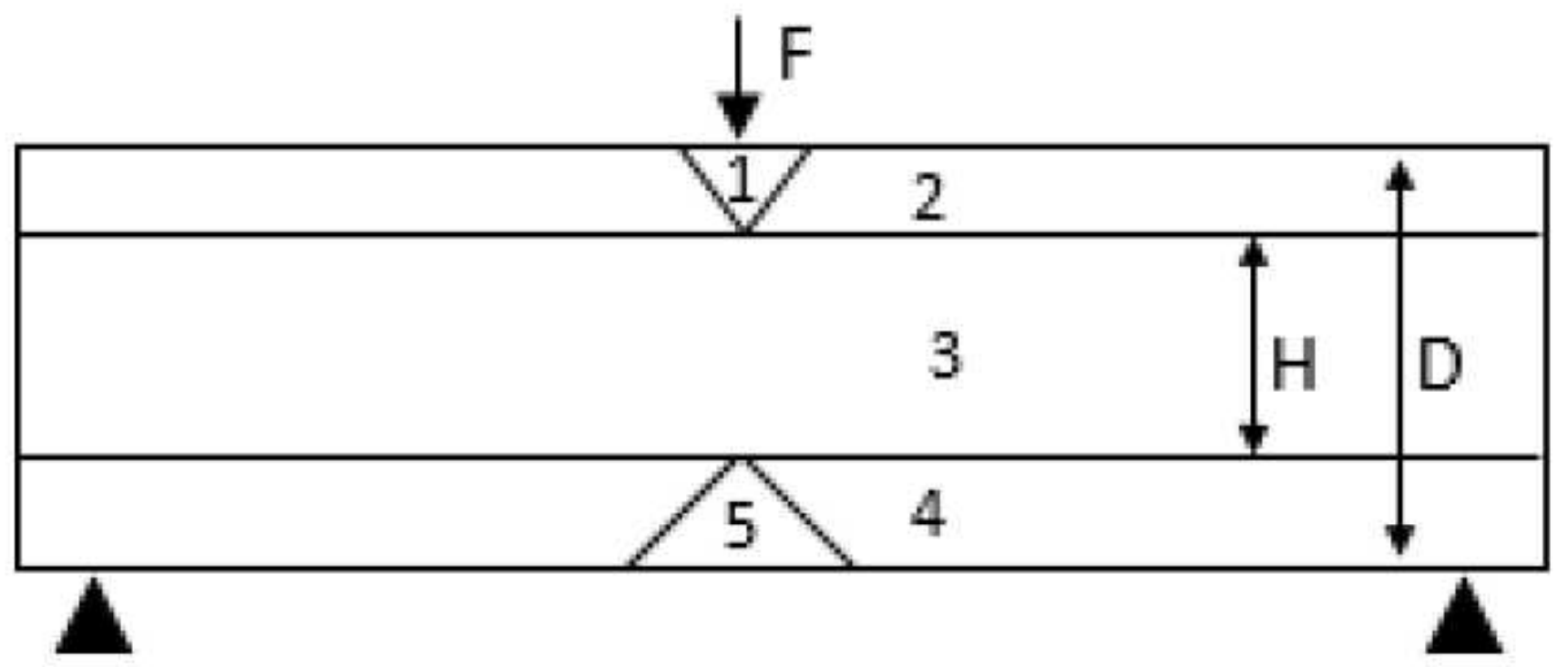

Figure 4

Division of elastoplastic deformation region

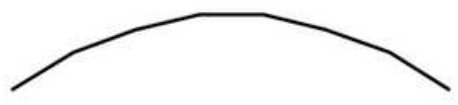

(1) Single bending

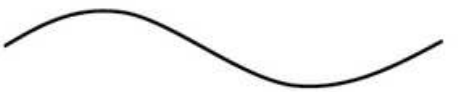

(2) S shape

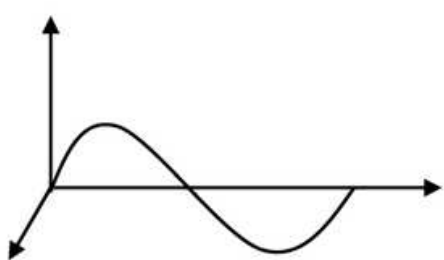

(3) Space distorting

Figure 5

Bending forms of gear shaft 


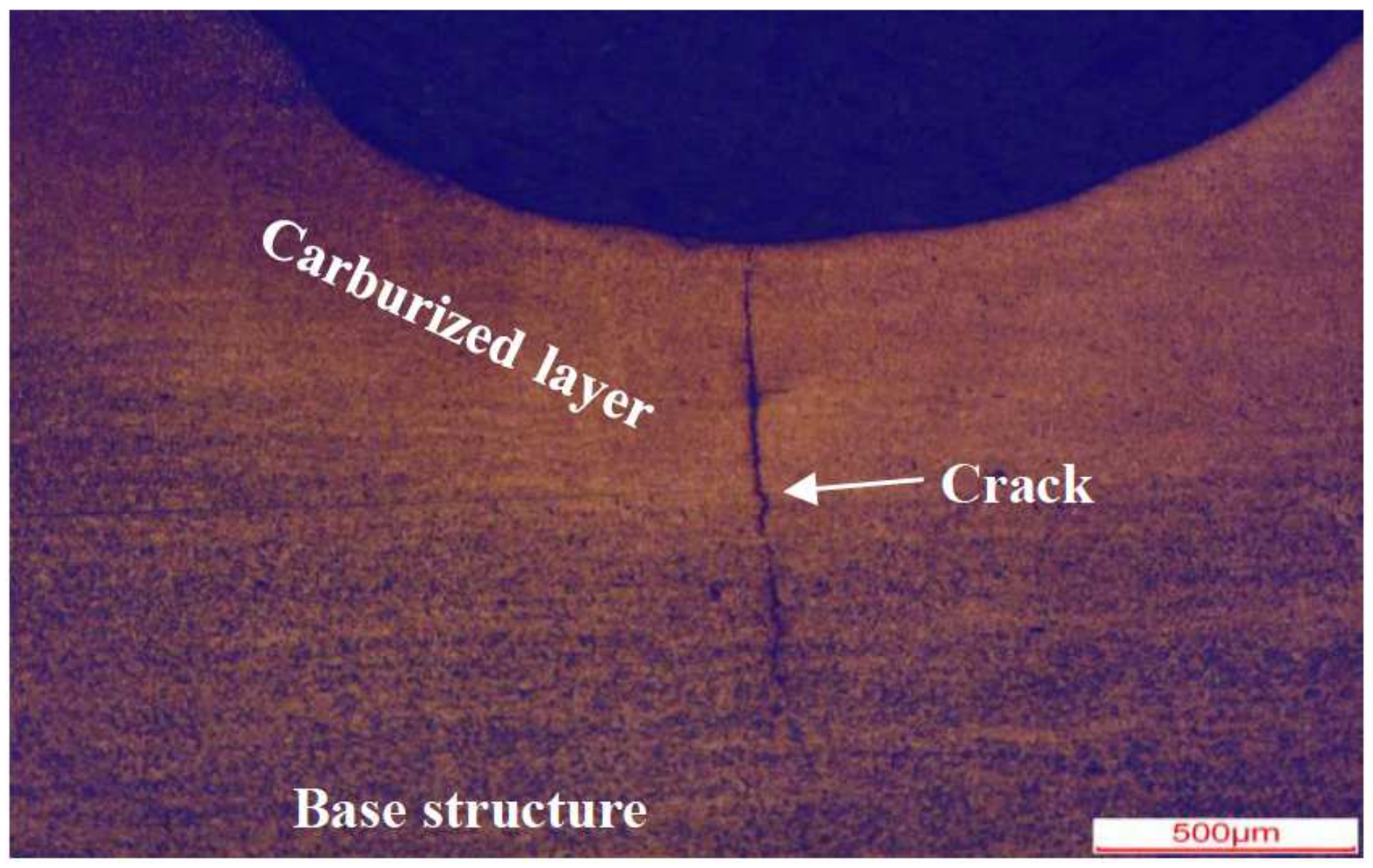

Figure 6

Carburized gear shaft straightening crack 


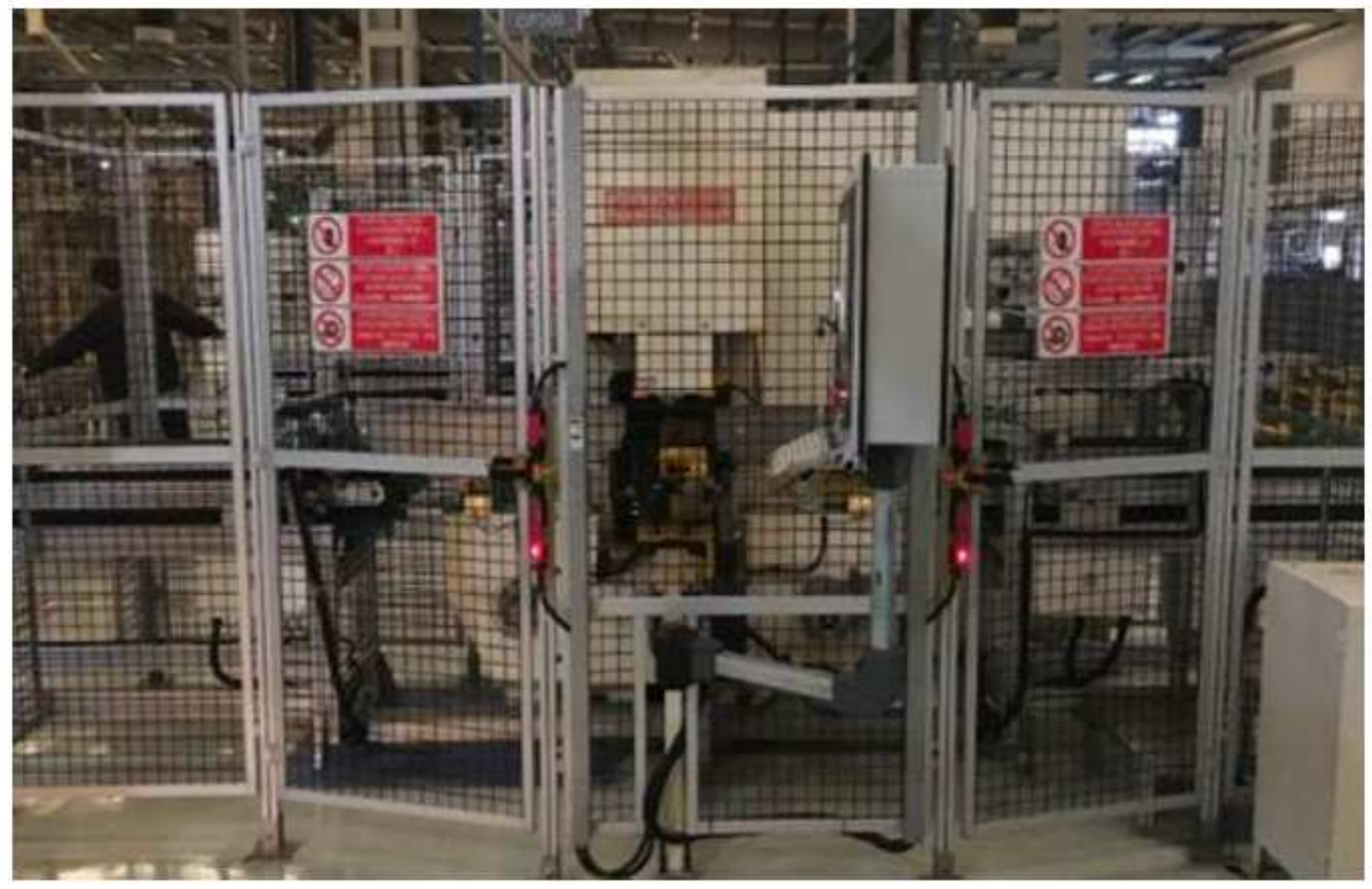

Figure 7

GALDABINI PAS/30 automatic straightening machine 


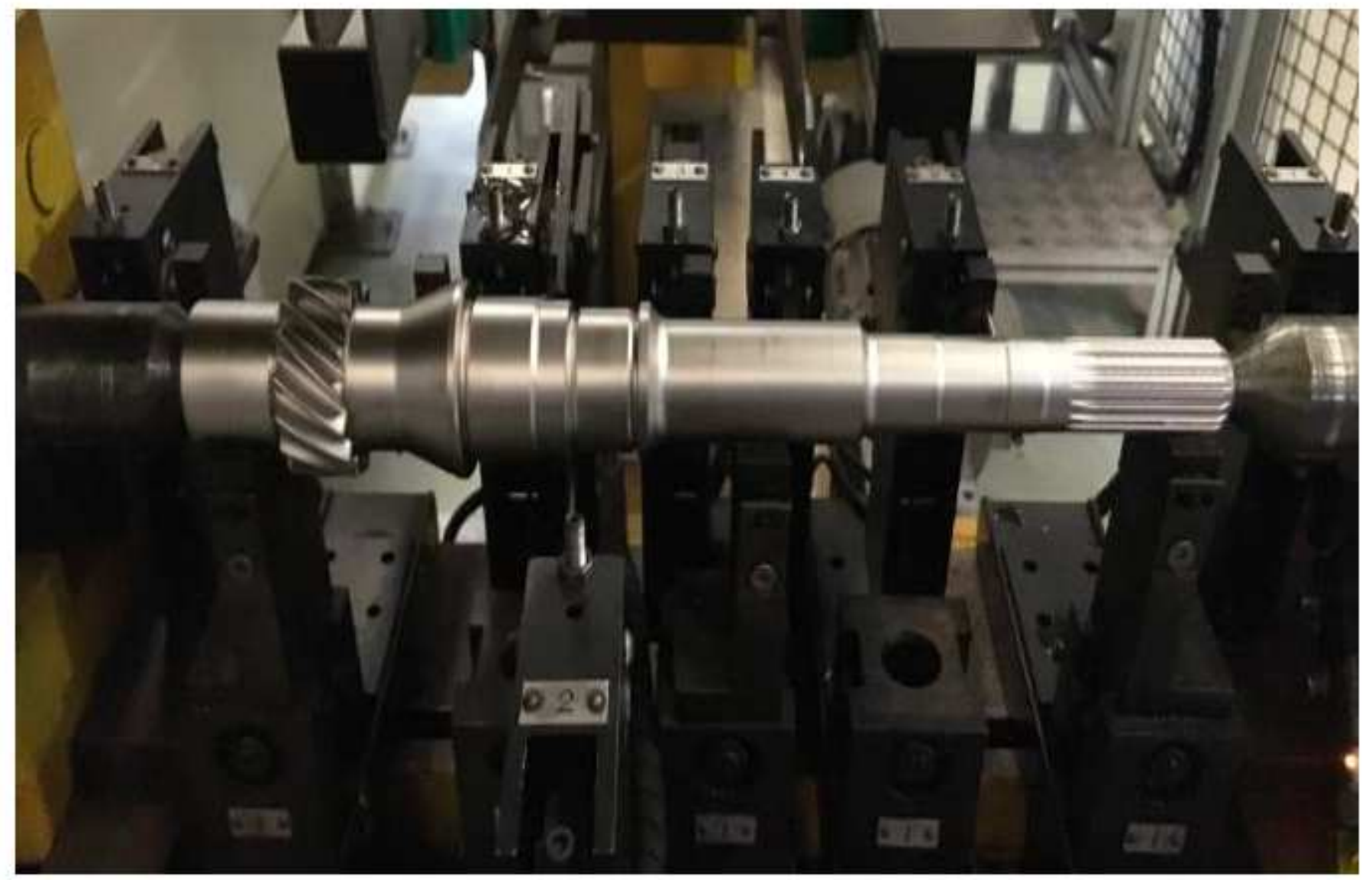

Figure 8

Working status of internal input shaft straightening

B

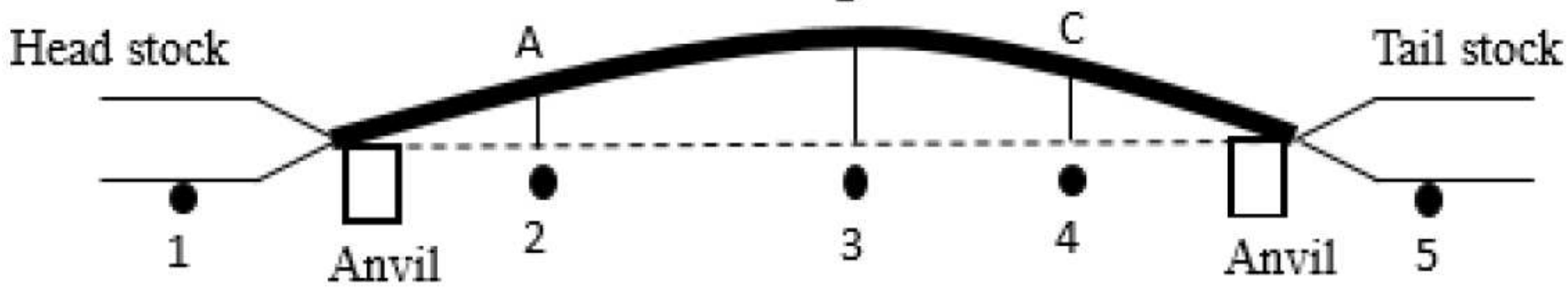

Figure 9

Curvature measurements system of PAS/30 straightening machine 


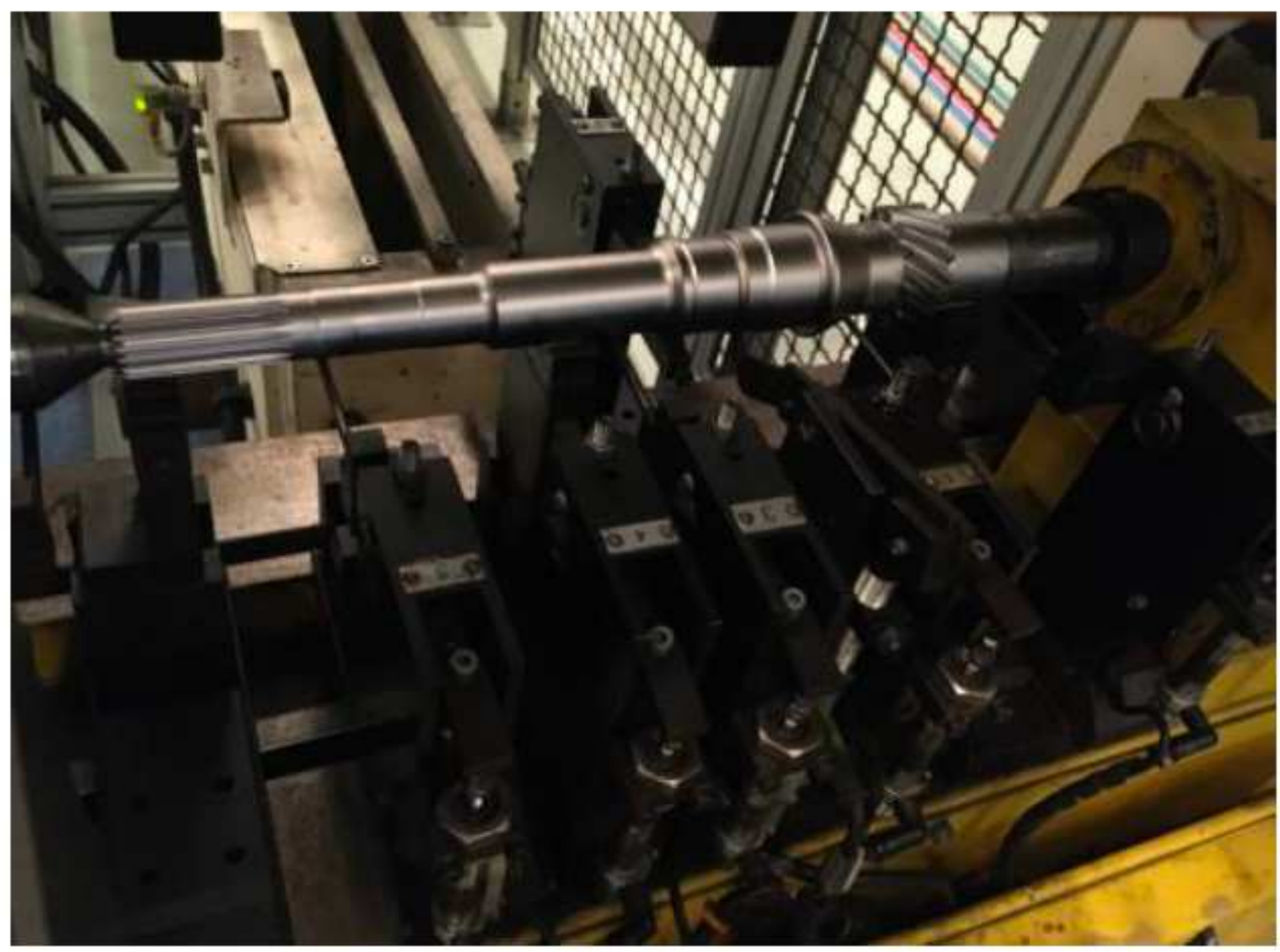

Figure 10

Layout of TL410 sensors 


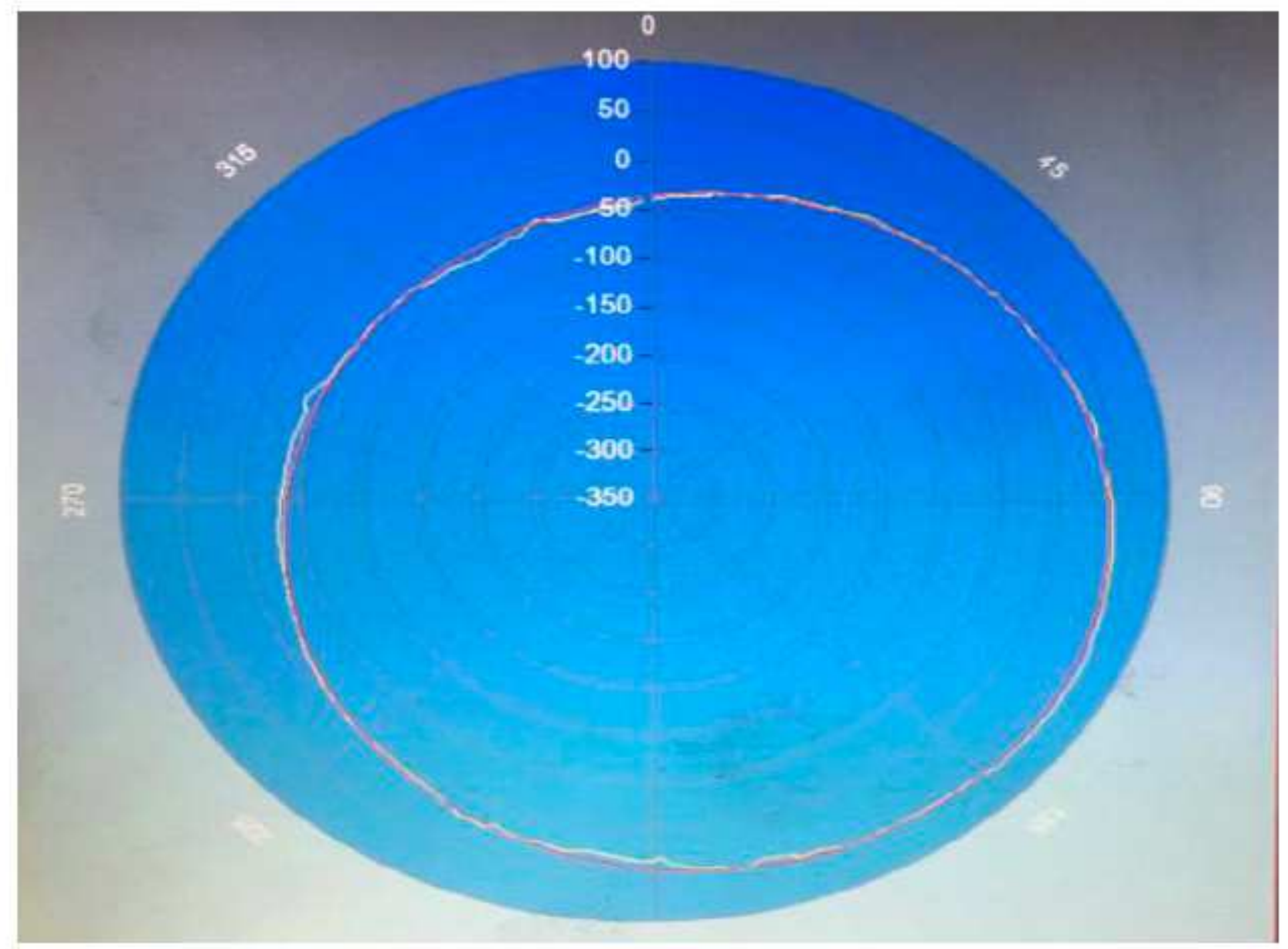

\section{Figure 11}

Polar coordinate graph

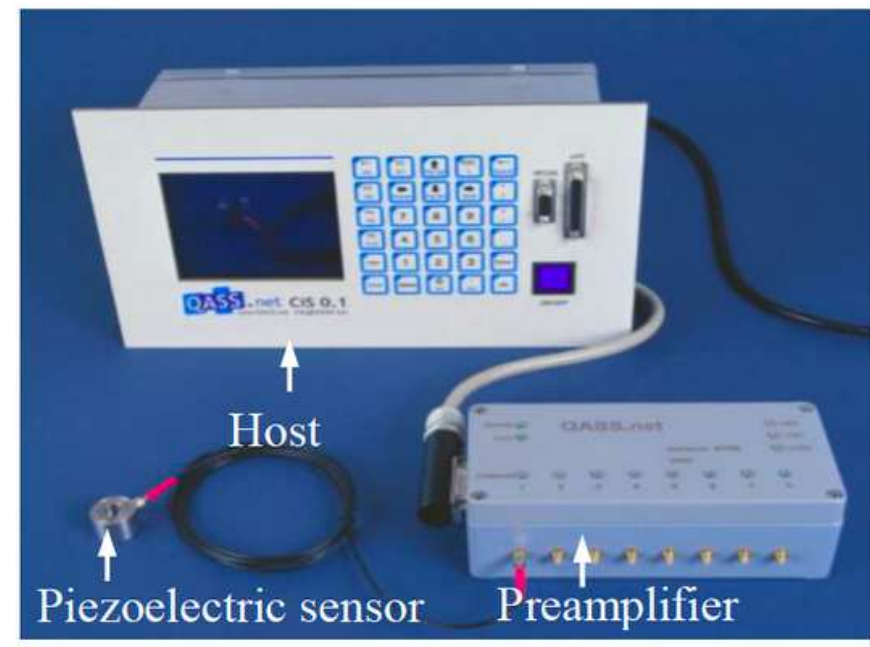

(a) Crack detector components

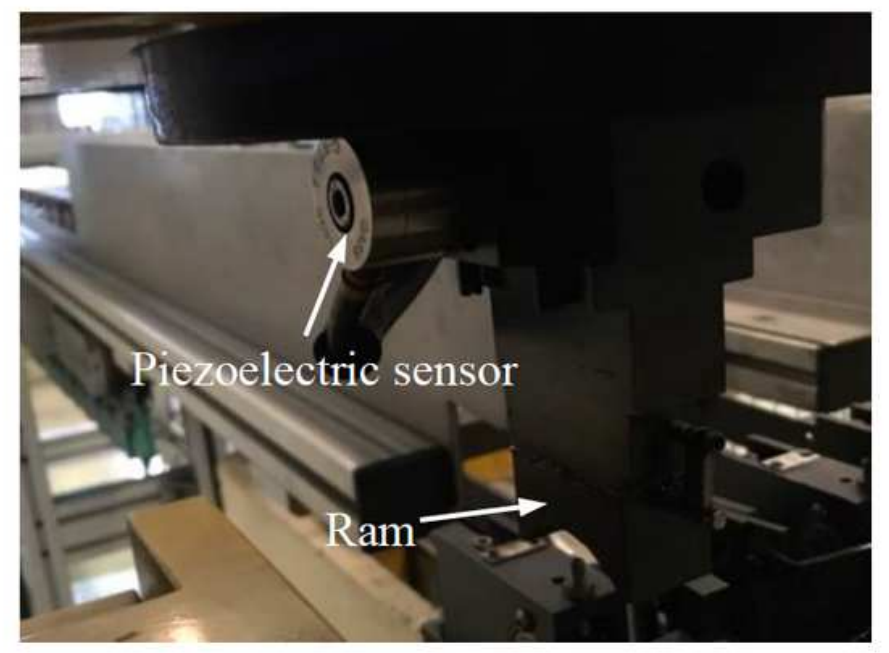

(b) Sensor location

Figure 12 
Crack detector components and sensor location

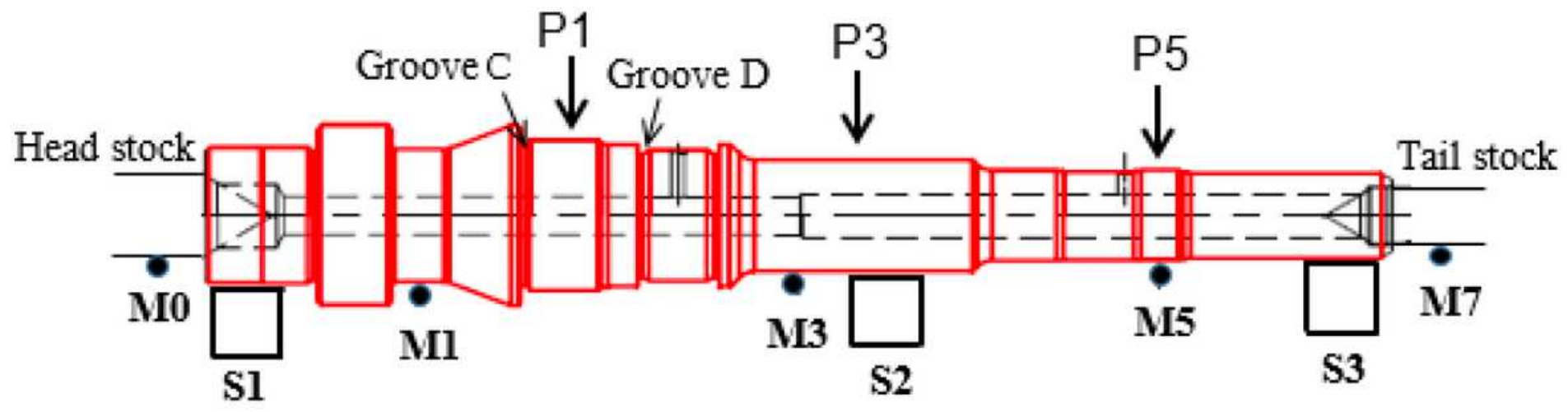

Figure 13

Layout of internal input shaft straightening 


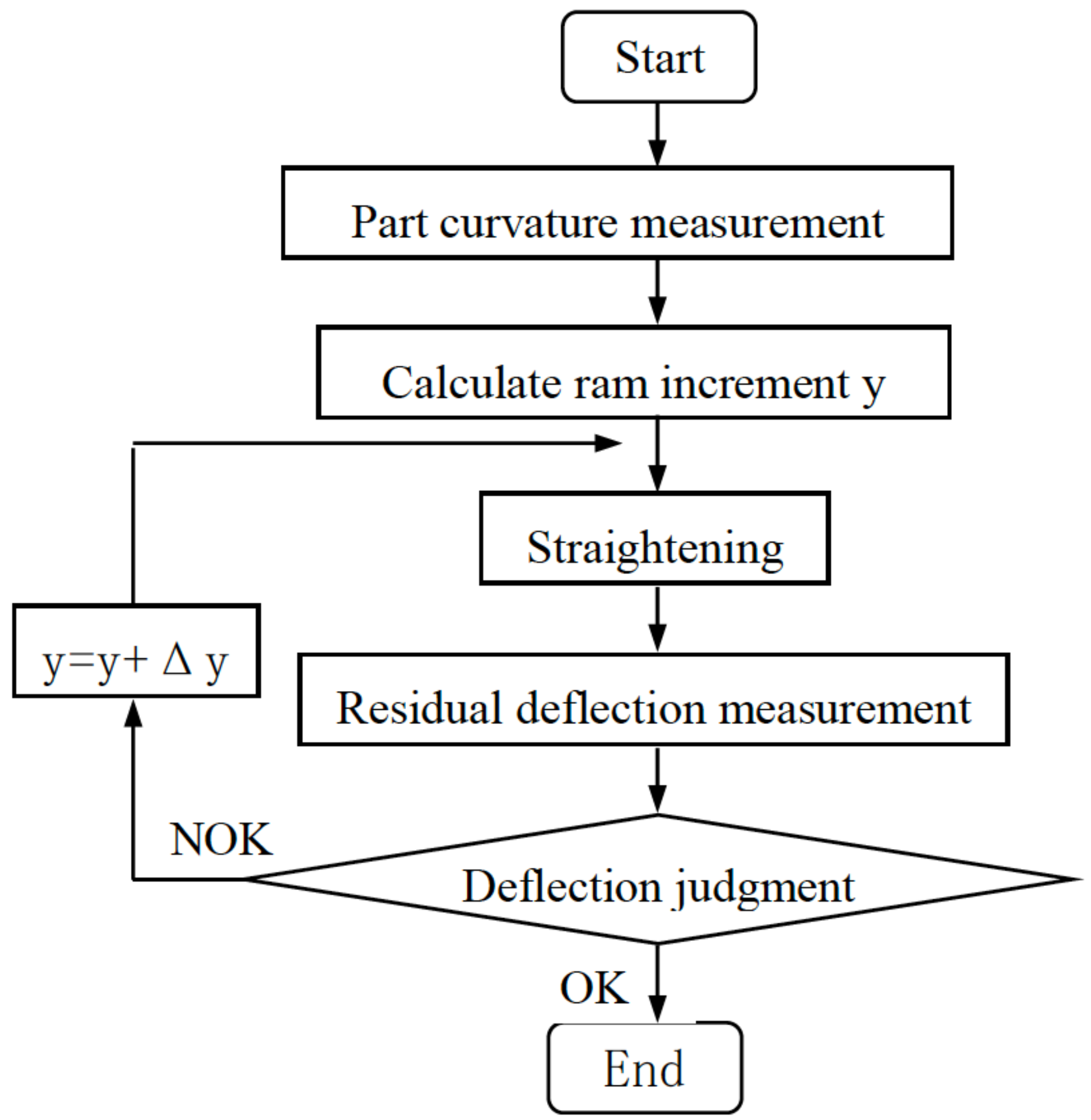

Figure 14

Small step progressive straightening process 


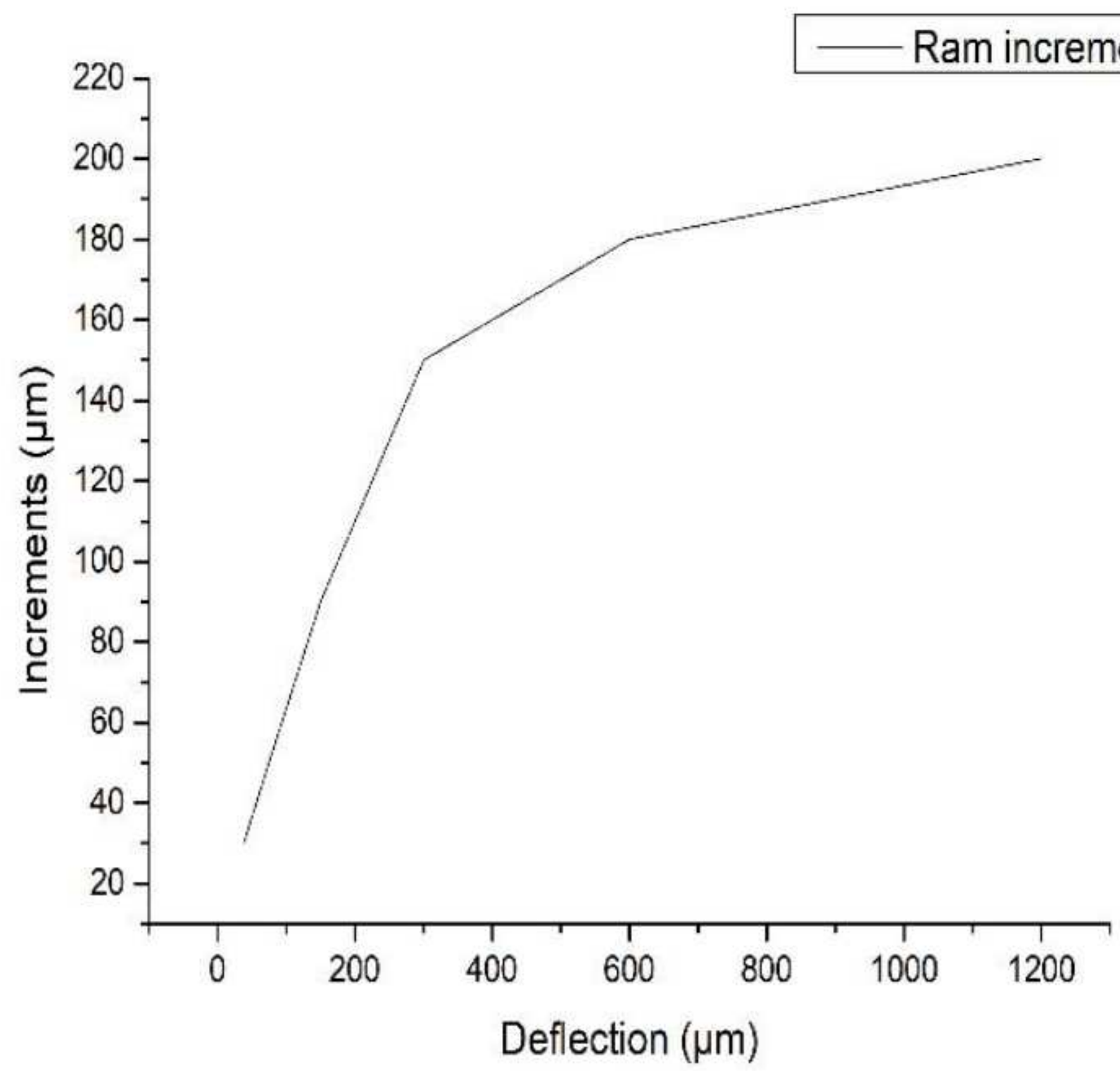

Figure 15

Schematic diagram of ram increment $(\Delta y)$ 


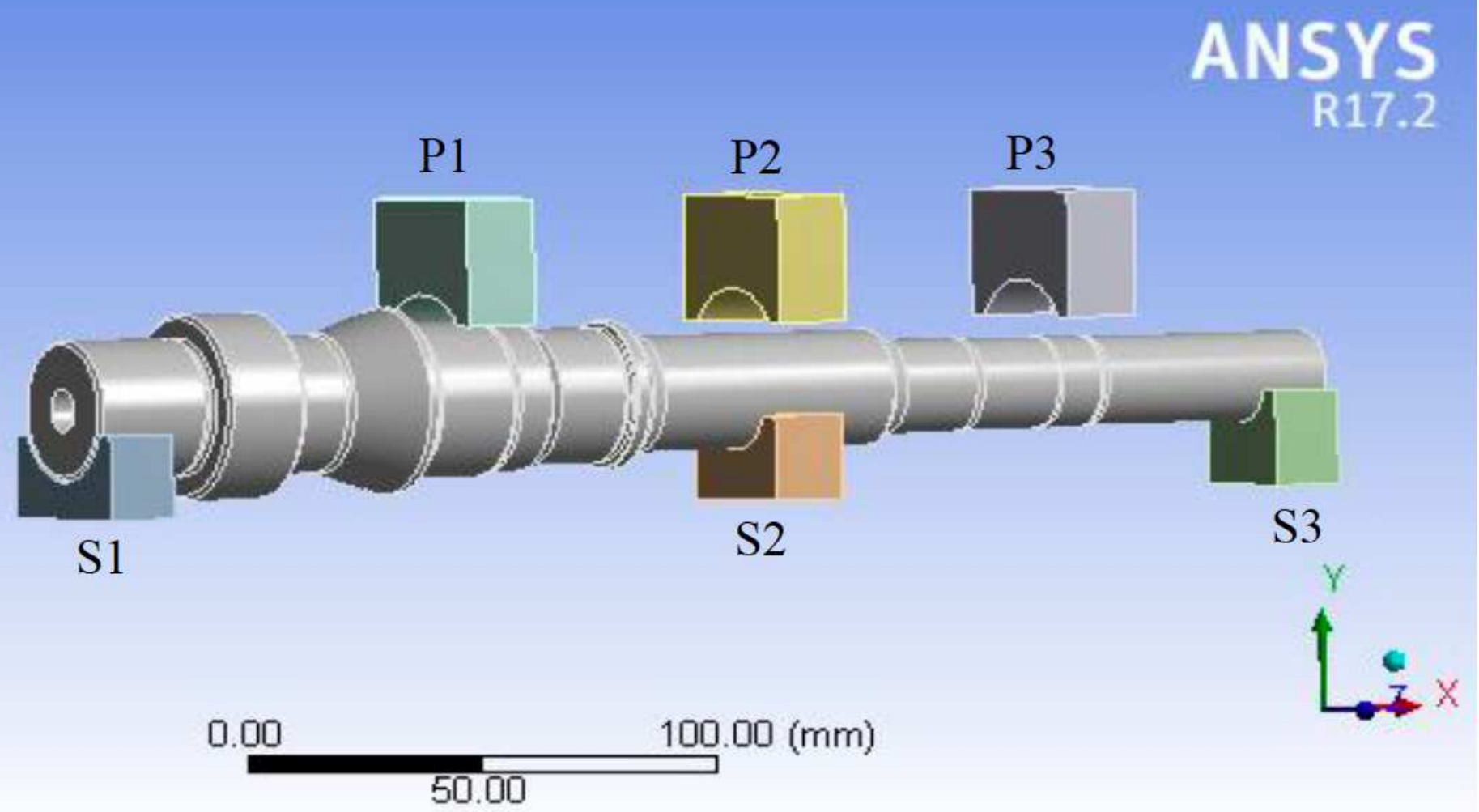

Figure 16

3D model of internal input shaft straightening

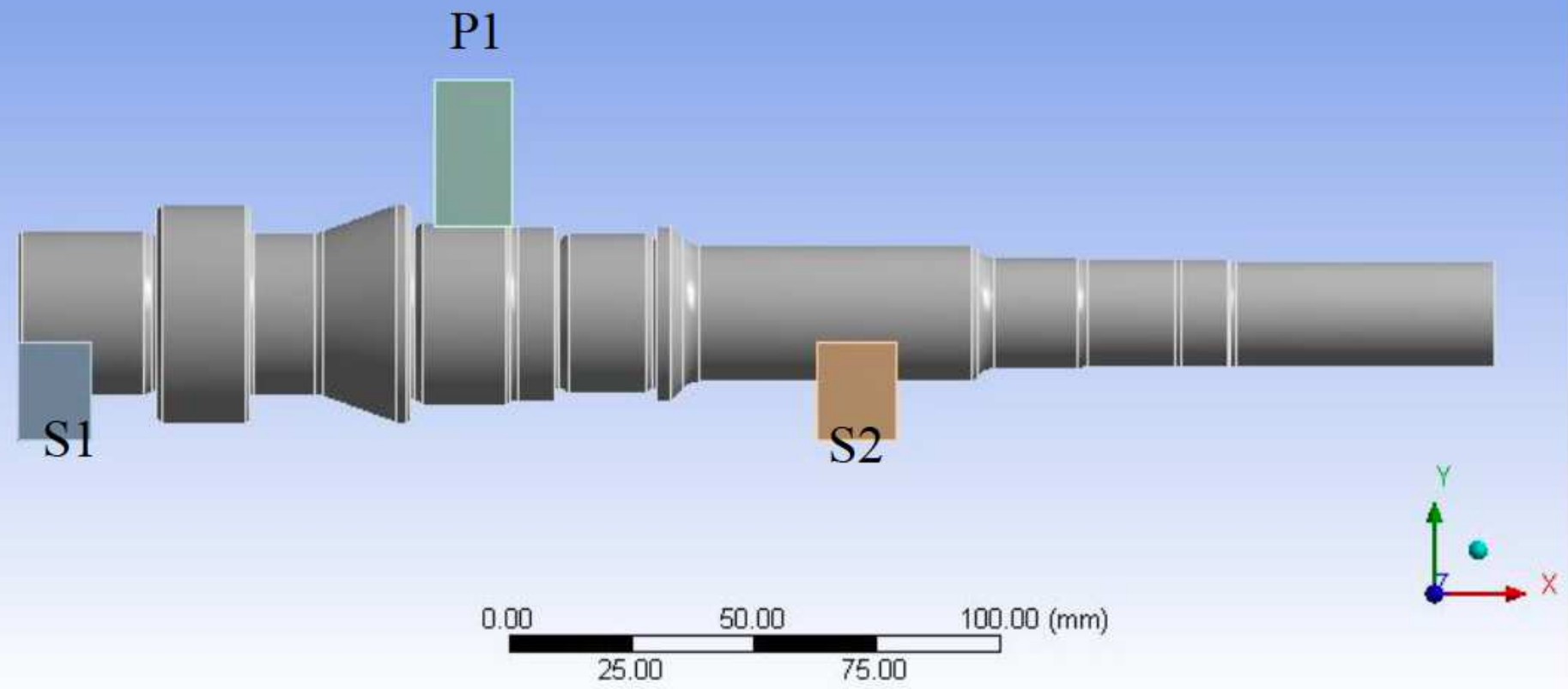

Figure 17 
3D model of P1 process

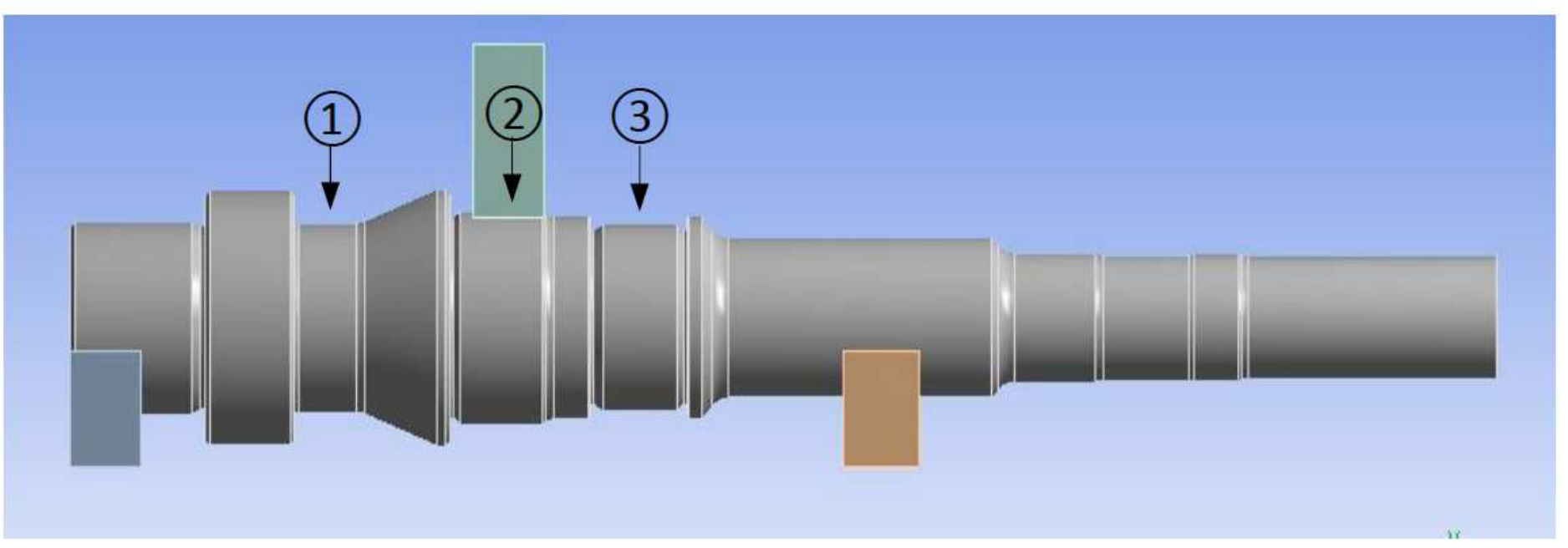

Figure 18

P1 point optional location distribution 
Unit: $M P_{a}$

Global Coordinate System

Time: 1

2020/1/8 23:59

236.14 Max 178.45 120.75 63.058

5.363

$-52.333$

$-110.03$

$-167.72$

$-225.42$

$-283.11 \mathrm{Min}$
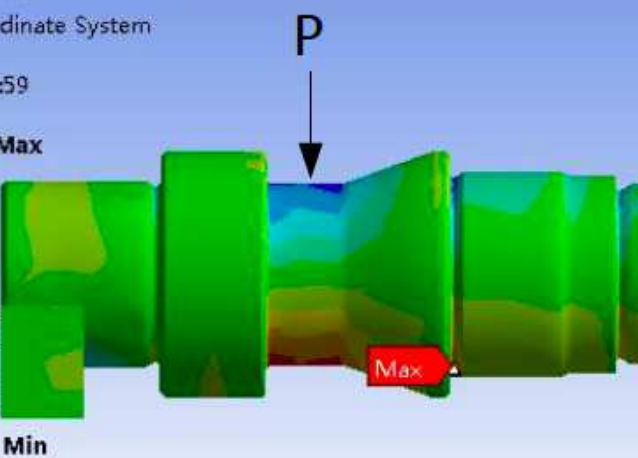

\section{ANSYS}

0.00

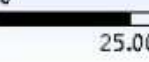

50.00

75.00

$100.00(\mathrm{~mm})$

\section{(a) Overall stress distribution}

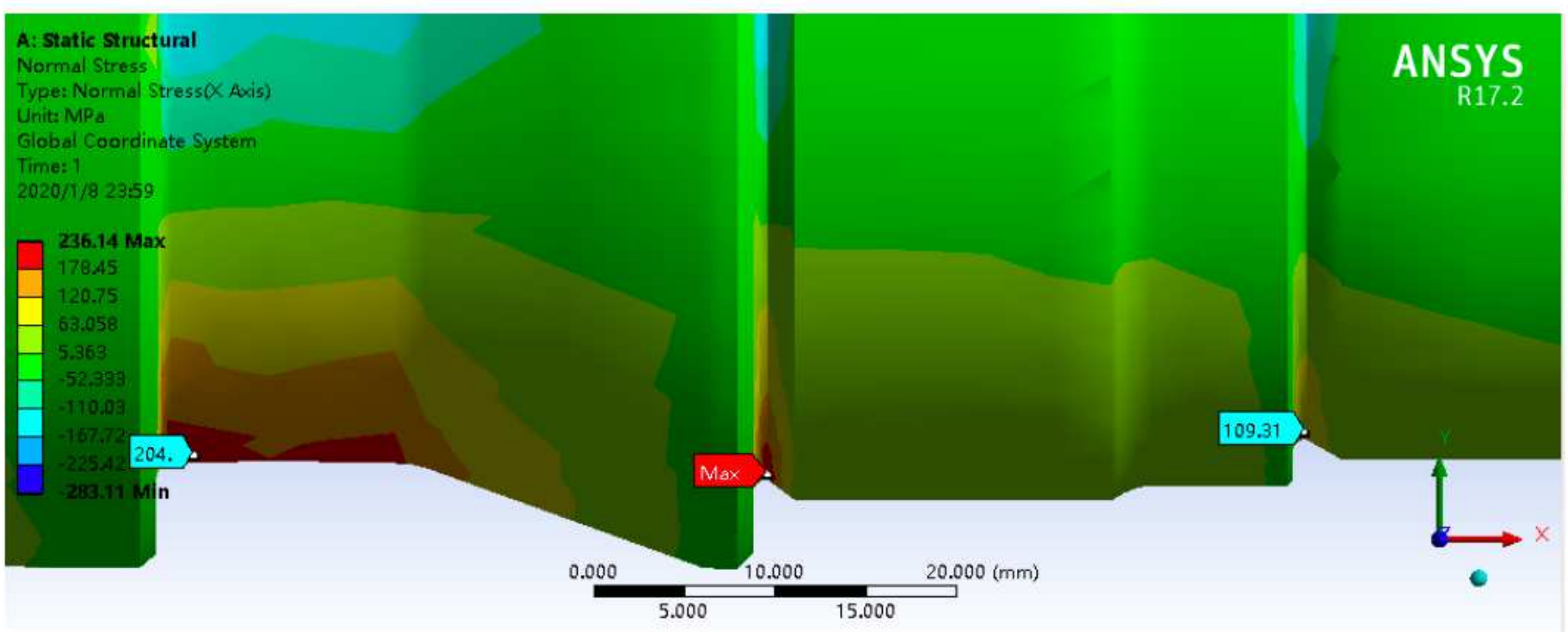

(b) Partial stress distribution

Figure 19

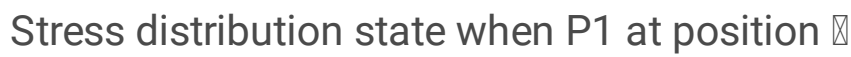




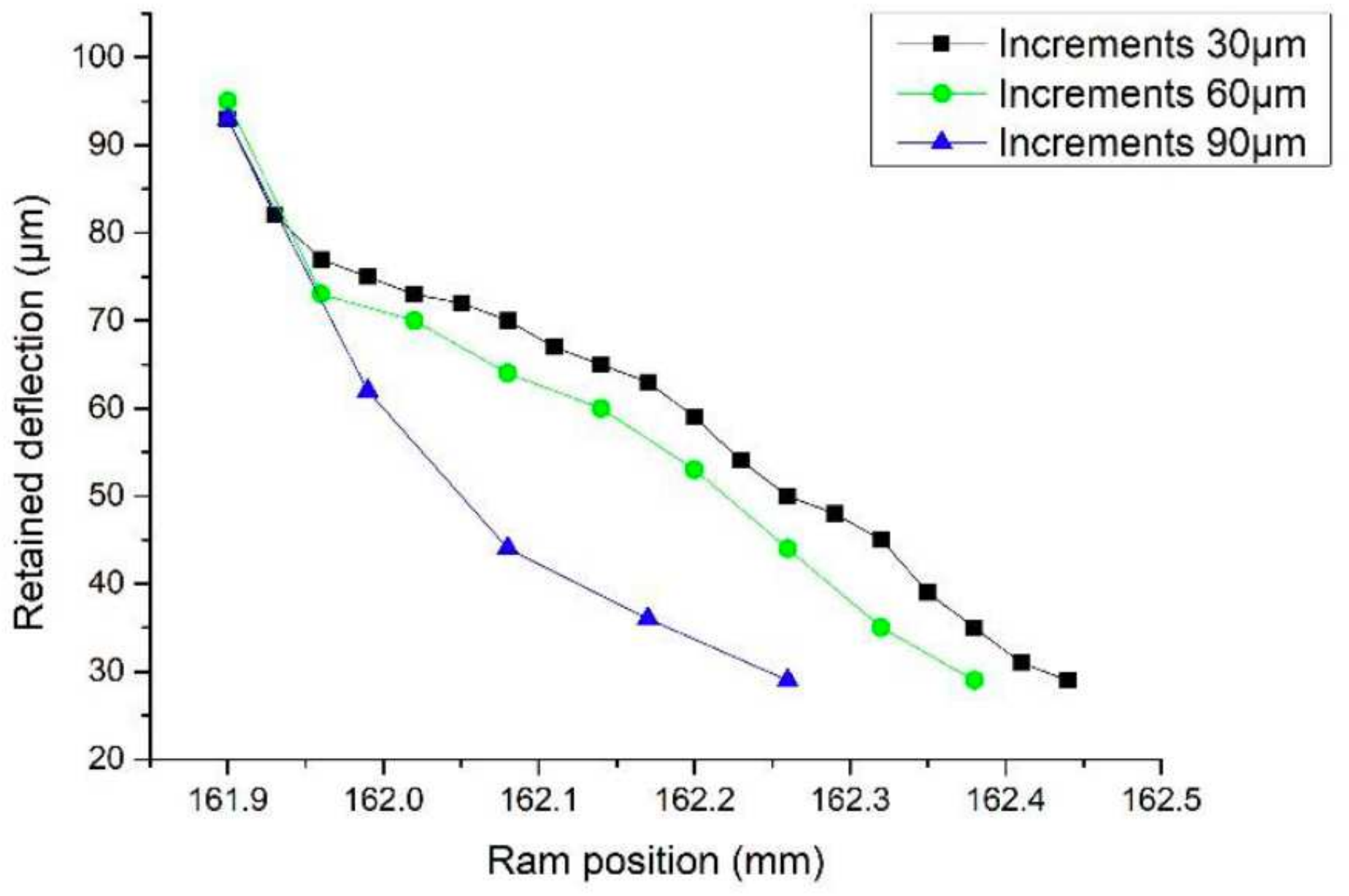

Figure 20

Increment retained deflection comparison 


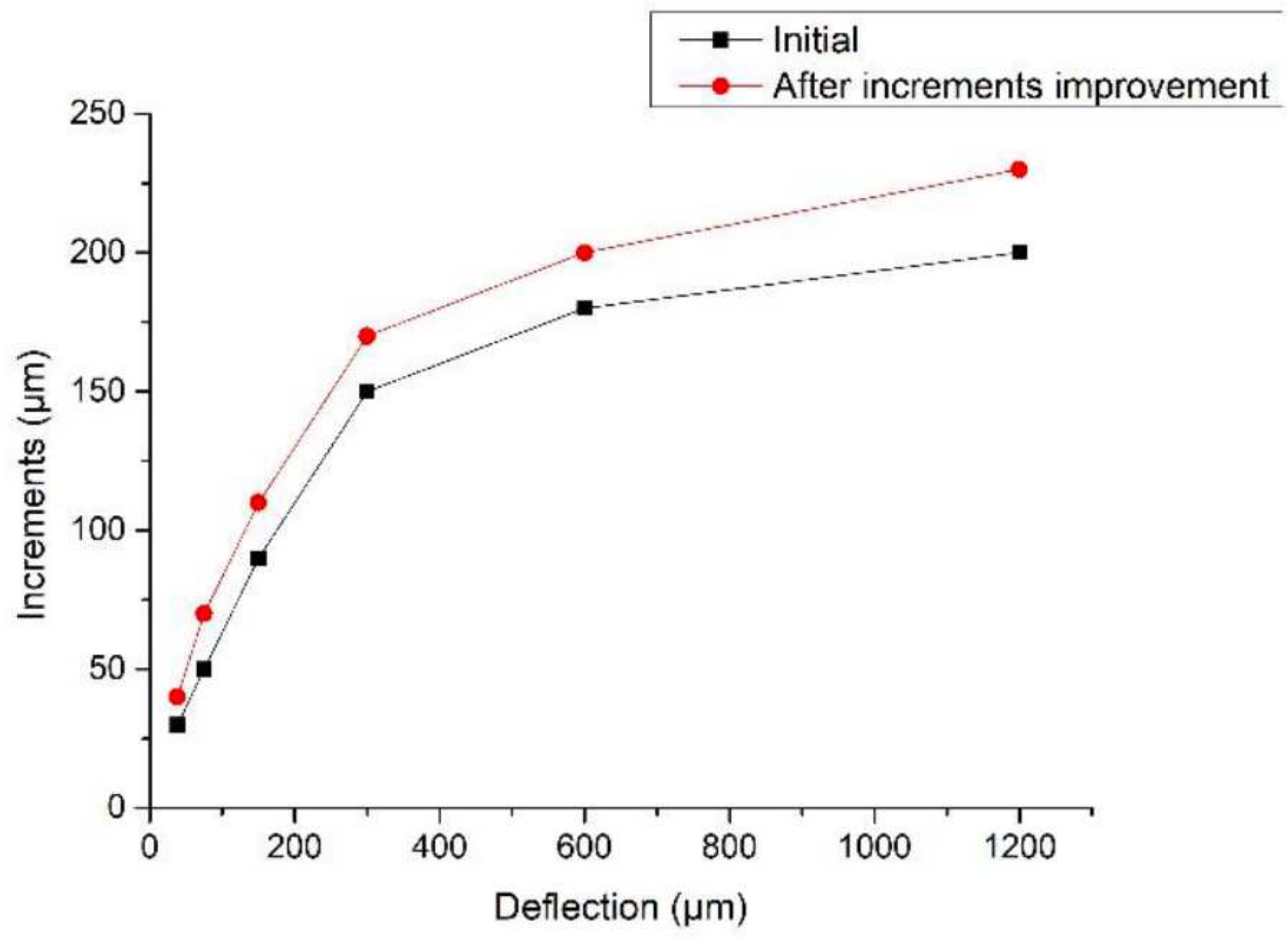

Figure 21

Incremental comparison of P1 before and after improvement 


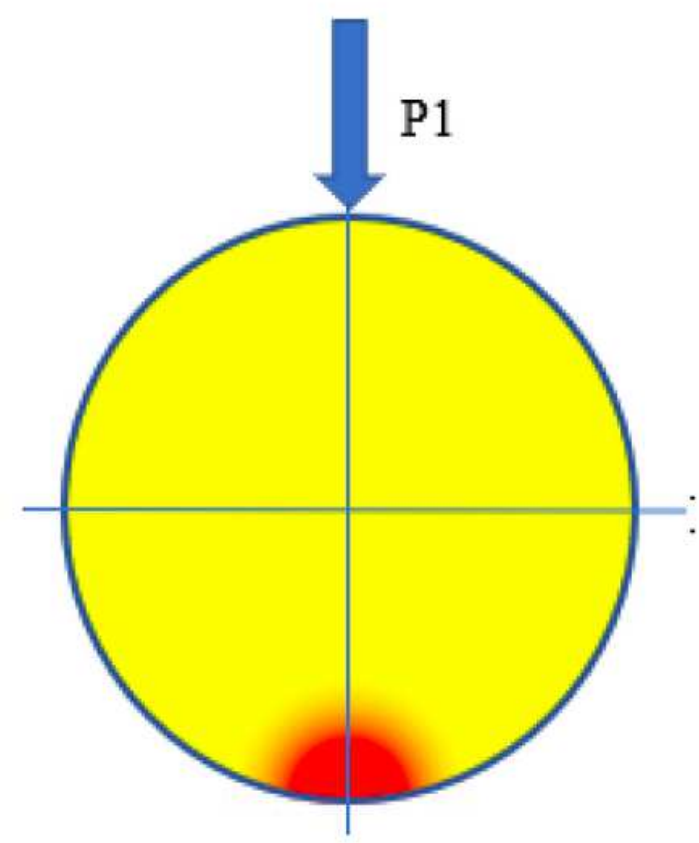

(a) Conventional straightening

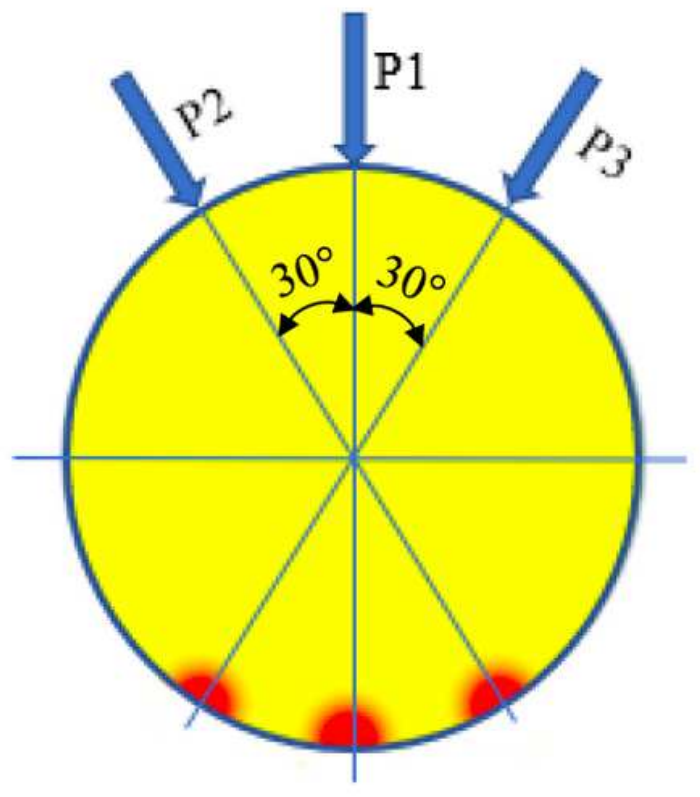

(b) Vector straightening

Figure 22

Comparison of conventional straightening and vector straightening

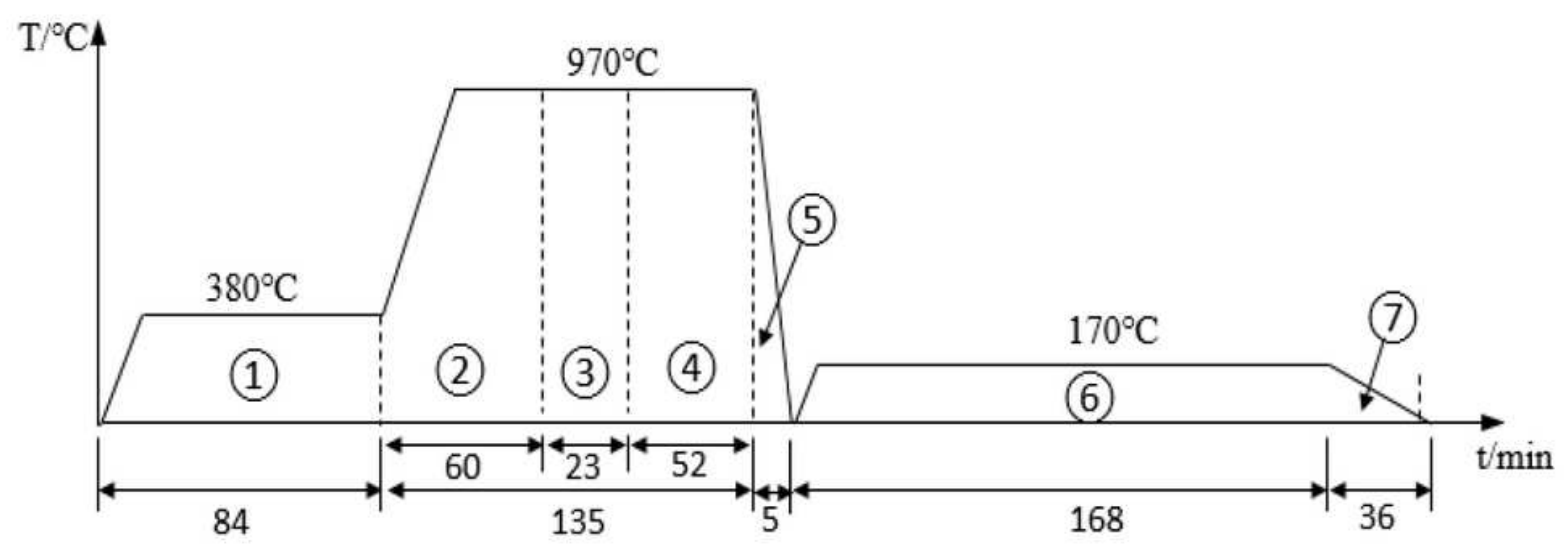

(1) Preheating

(2) Heating

(3) Carburizing

(4) Diffusion

(5) Quenching

(6) Tempering

(7) Cooling

Figure 23

Temperature time curve of heat treatment process 


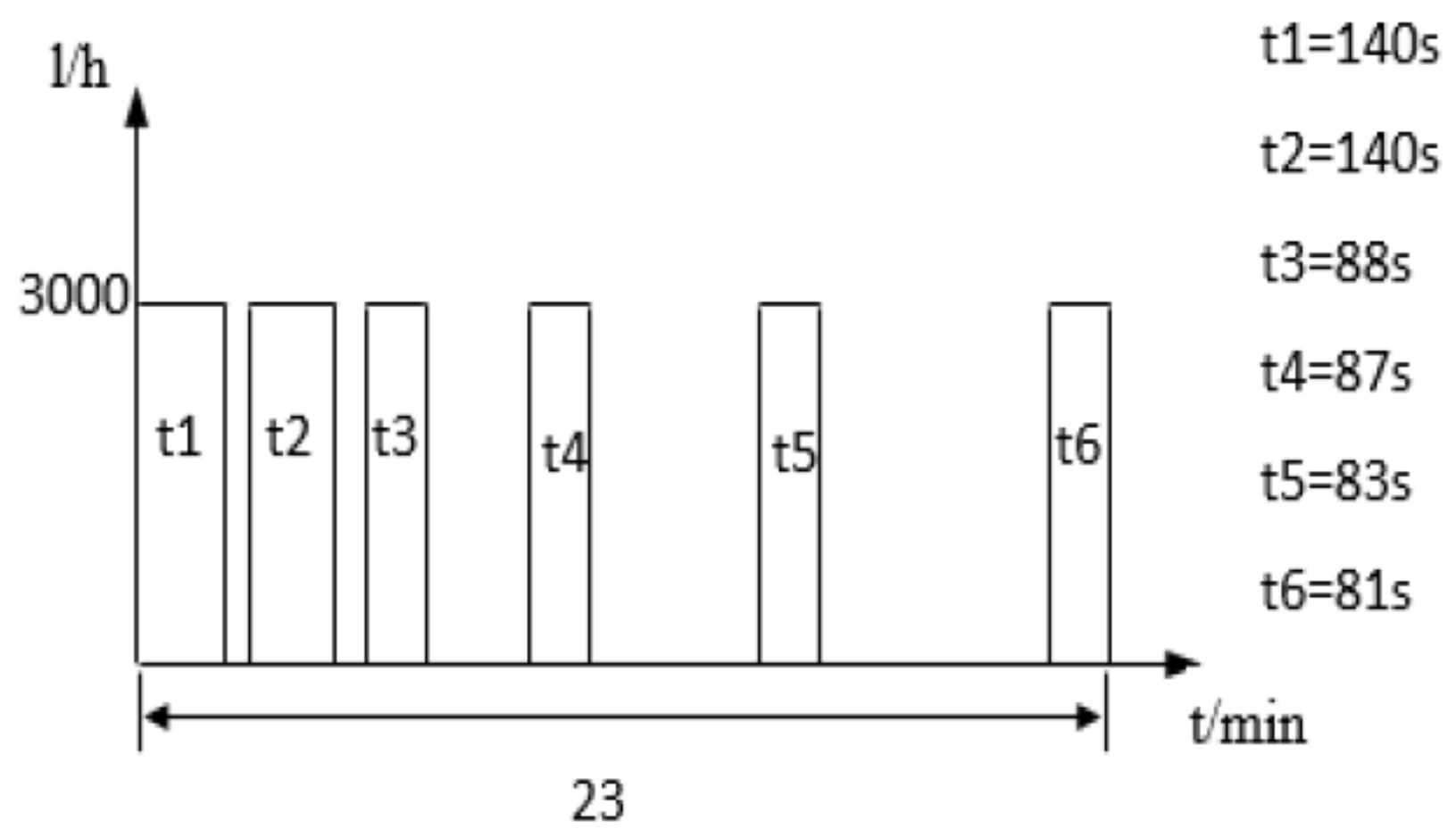

Figure 24

Carburizing pulse

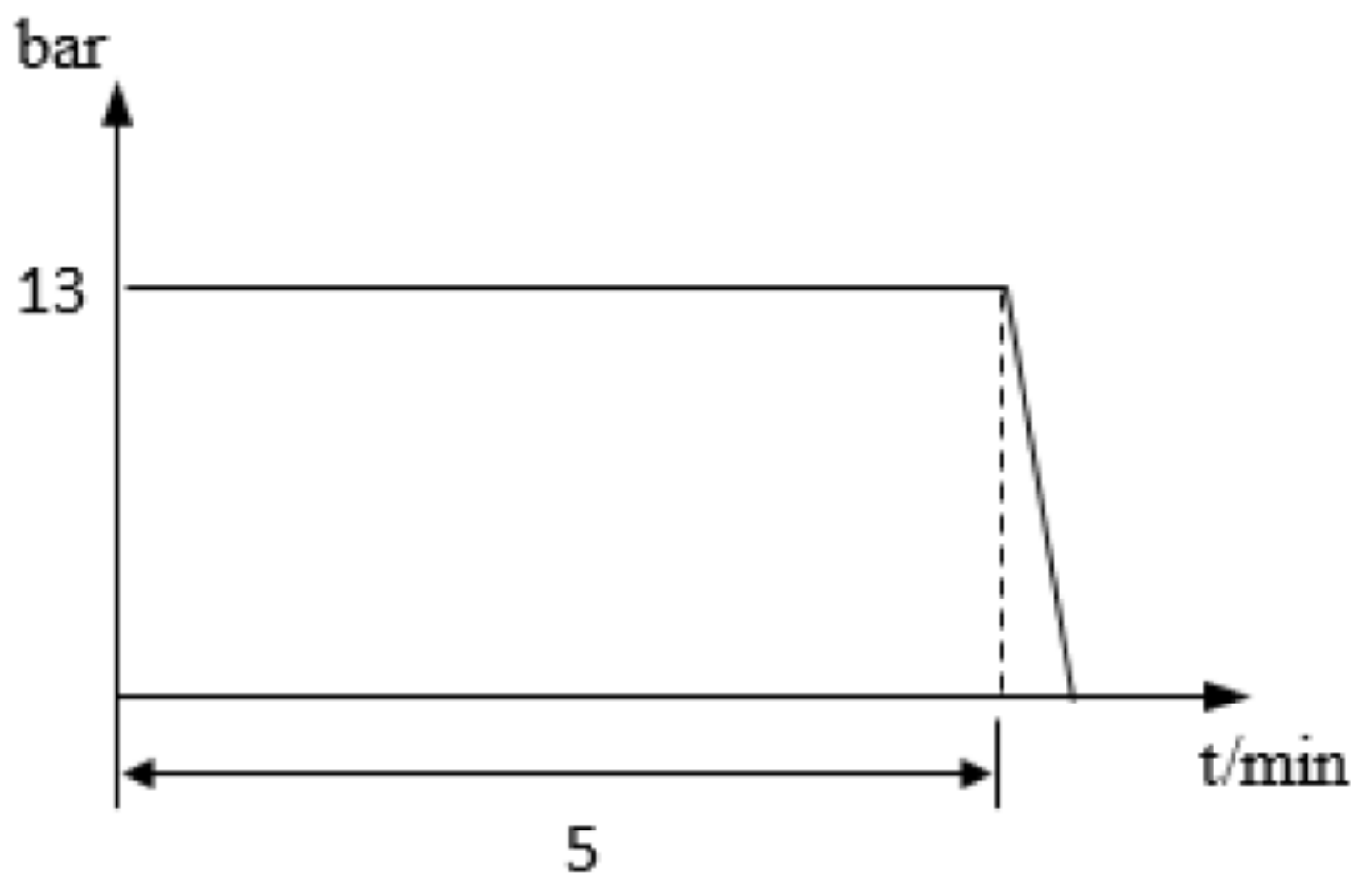

Figure 25 


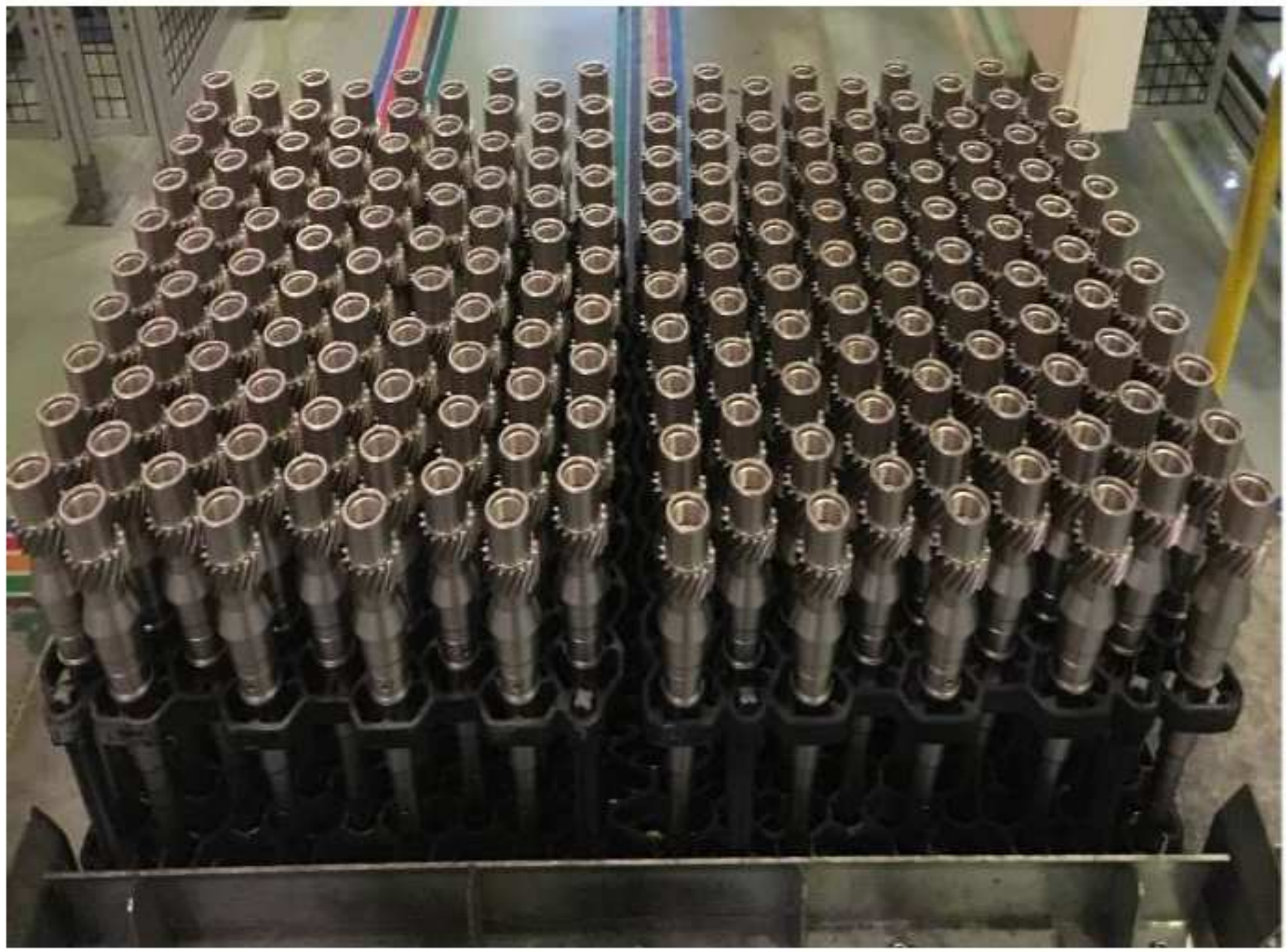

Figure 26

Parts loading station 


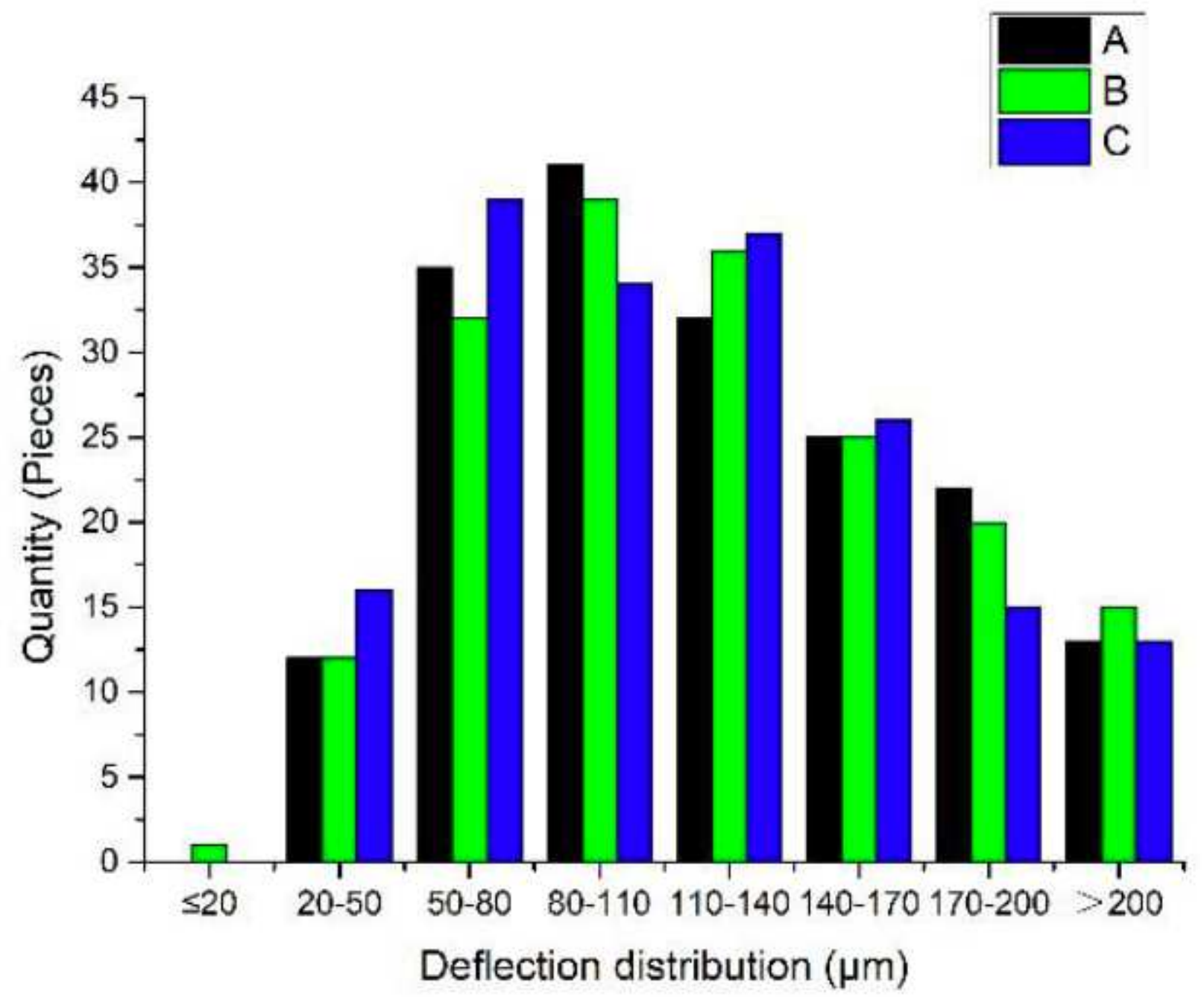

Figure 27

Deflection distribute 
(a) Tensile sample

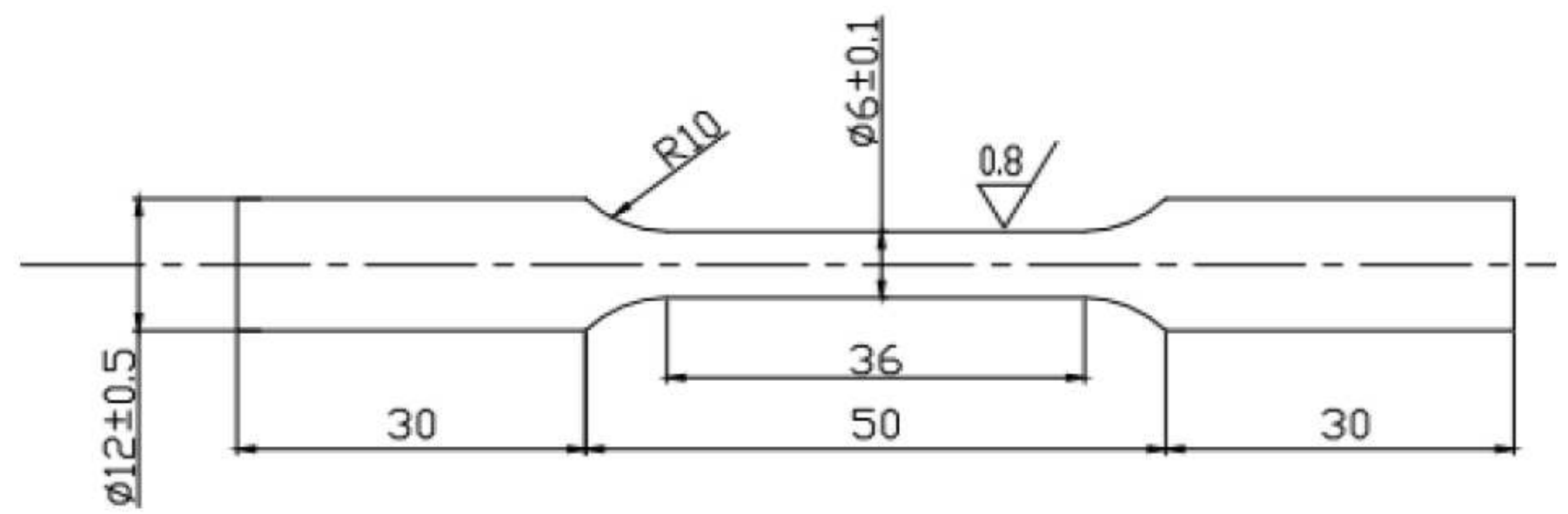

(b) Tensile sample size

Figure 28

Tensile sample and size 


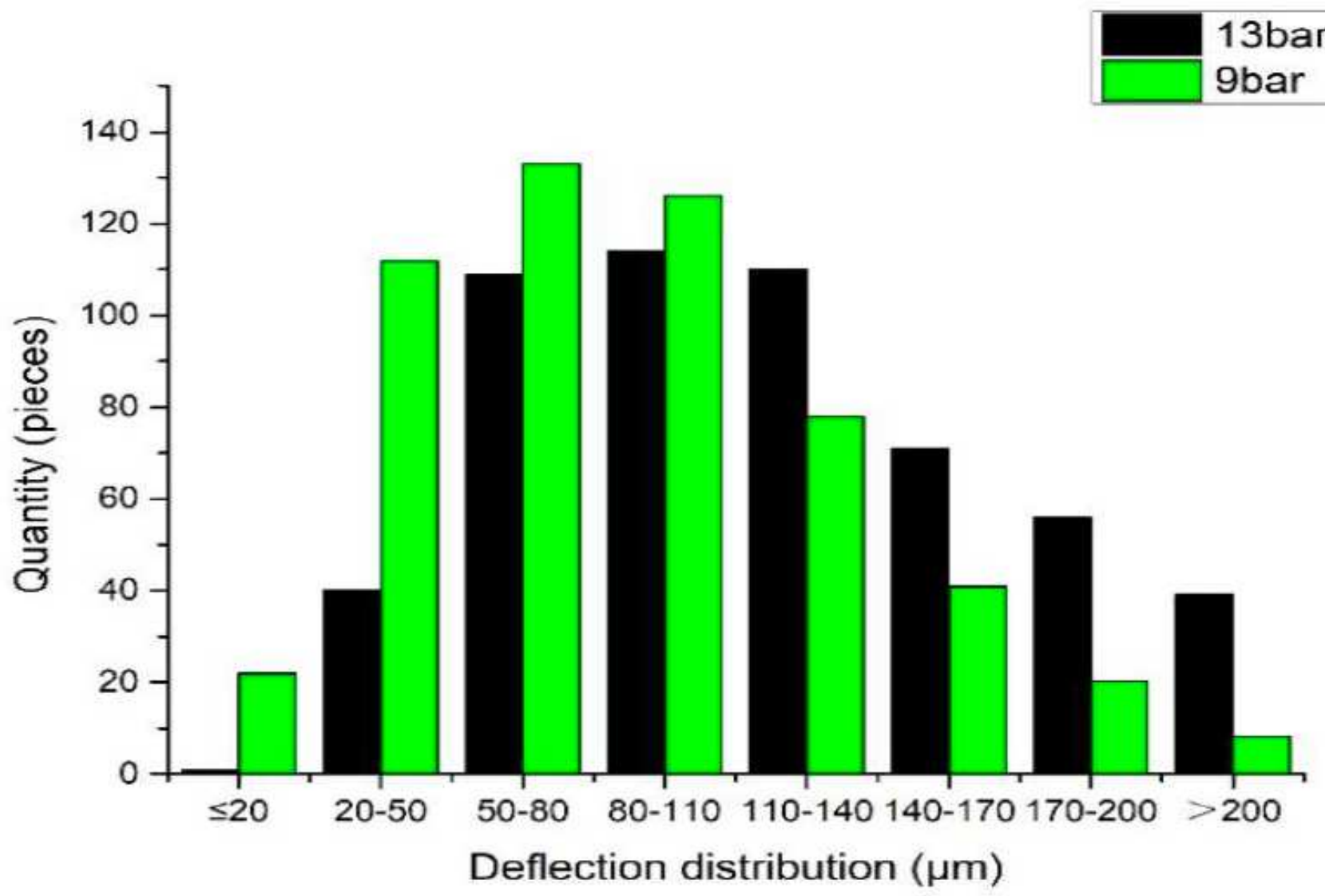

Figure 29

Deflection distribution of parts under different gas quenching pressures 


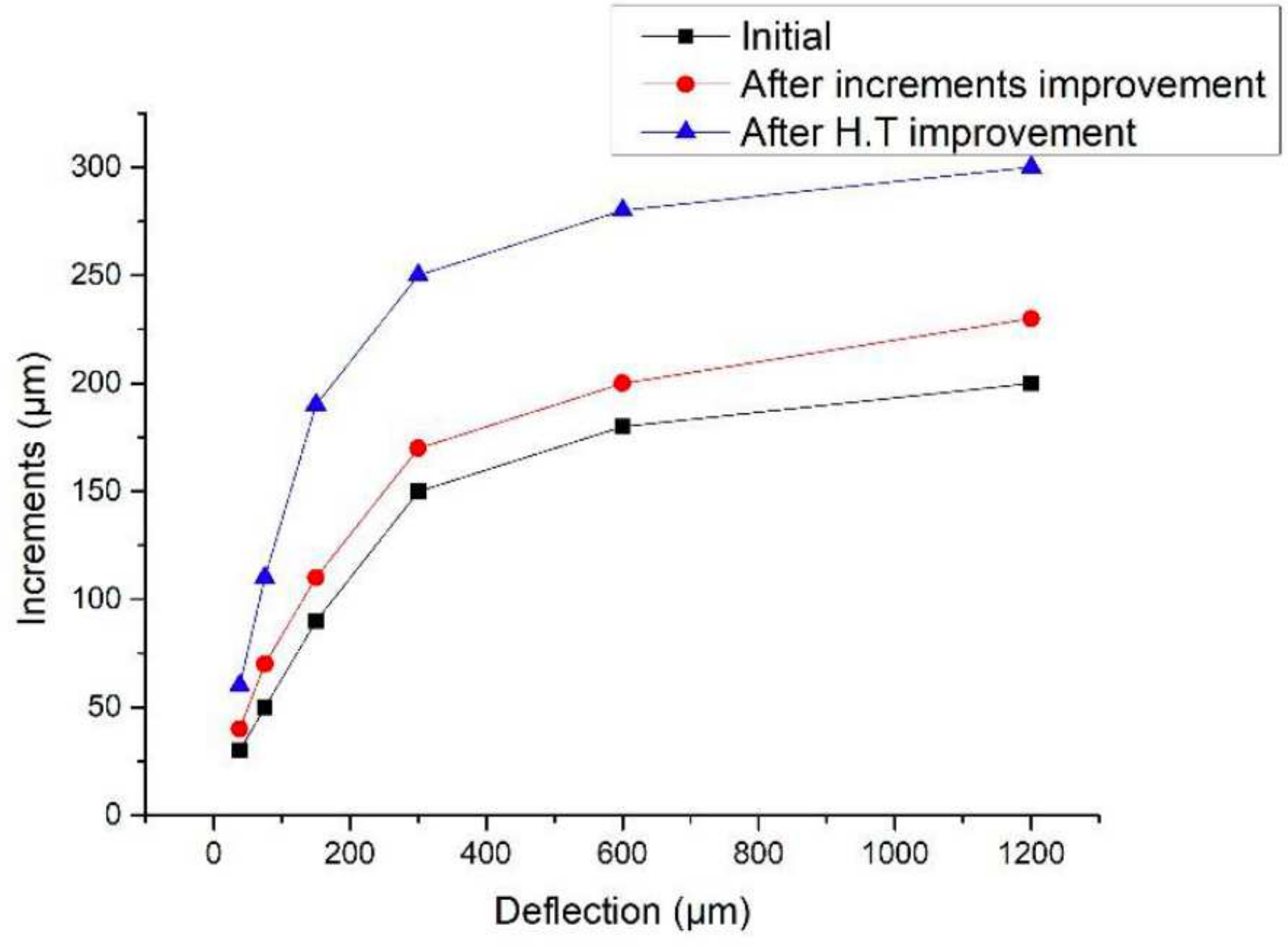

Figure 30

Incremental comparison of P1 before and after improvement 


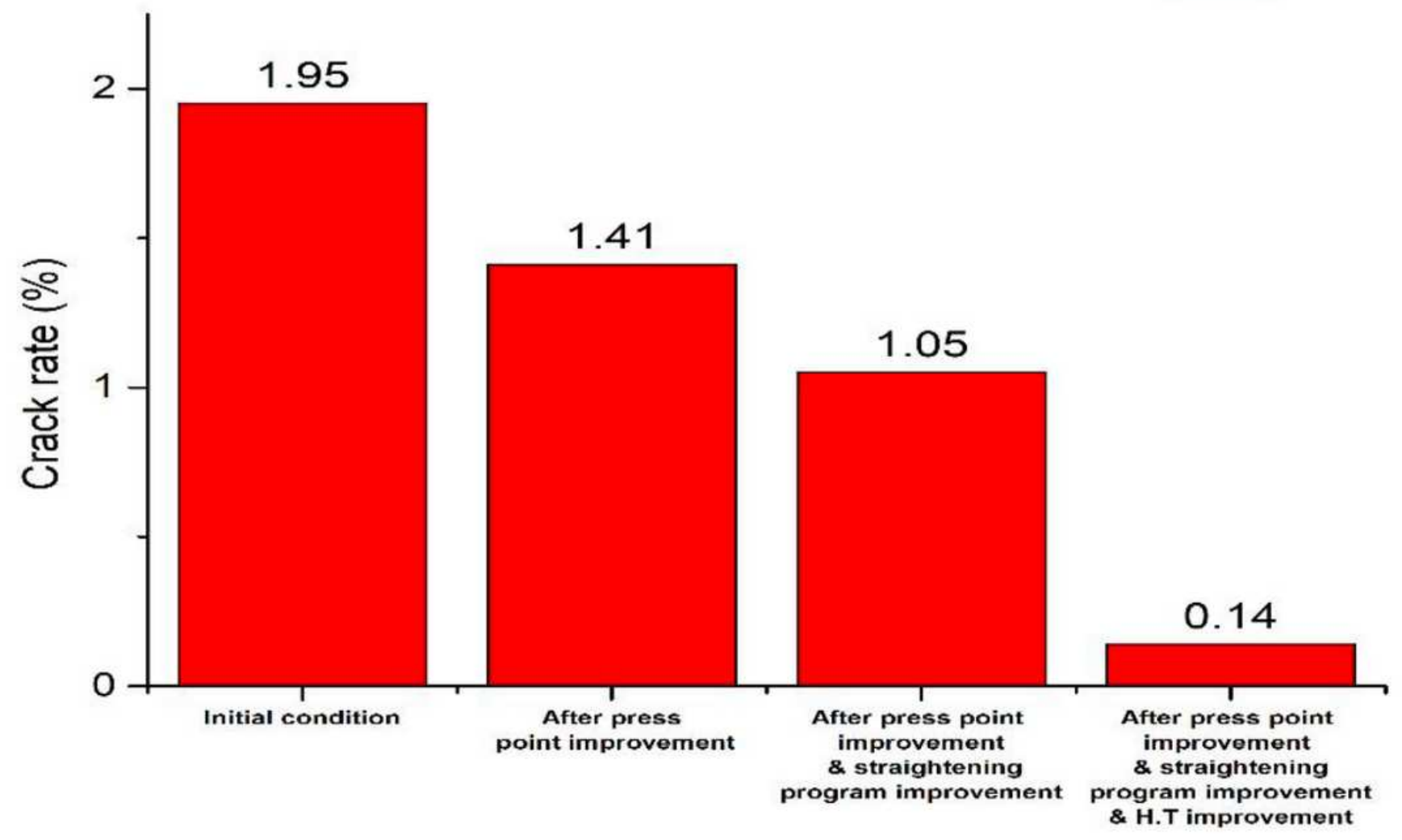

Figure 31

Straightening crack rate comparison after improvement measures 